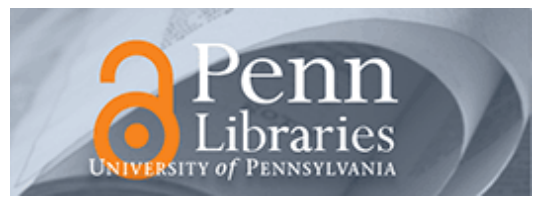

Studies in Visual Communication

Volume 7

Issue 4 Fall 1981

Article 3

1981

\title{
Analysis of Historical Photographs: A Method and a Case Study
}

James Borchert

\section{Recommended Citation}

Borchert, J. (1981). Analysis of Historical Photographs: A Method and a Case Study. 7 (4), 30-63.

Retrieved from https://repository.upenn.edu/svc/vol7/iss4/3

This paper is posted at ScholarlyCommons. https://repository.upenn.edu/svc/vol7/iss4/3

For more information, please contact repository@pobox.upenn.edu. 


\section{Analysis of Historical Photographs: A Method and a Case Study}




\title{
Analysis of Historical Photographs: A Method and a Case Study
}

\author{
James Borchert
}

Documentary photography has vast and as yet unrealized potentialities for recording as well as for presenting data that should be of vital interest to social scientists and historians.... Documentary photography is a new means with which the historian can capture important but fugitive items in the social scene. - Roy Stryker and Paul Johnstone (1940)

While social scientists have been recording and analyzing still photographs (and film) for a number of years, historians have used visual records sparingly. ${ }^{1}$ Undoubtedly, a large part of the cause of historians' neglect is their strong tendency to rely on traditional written sources. ${ }^{2}$ Having developed skills in "textual analysis," historians have concentrated on these sources. In contrast, social scientists, who have often found it necessary to collect their own data, have been much more adventurous. The end result is that social scientists have increasingly developed more sophisticated research methods while historians are only now beginning to approach new sources of information.

Despite this condition, there has long been an interest in photographs as a means of recording "nonrecurring events" for both historical interest and analysis. Documentary photographers were among the first to see the value of photographers; the work of Roger Fenton on the Crimean War and that of American photographers on the Civil War reflected, along with a desire for financial gain, a concern for preserving "nonrecurring" events. As Alexander Gardner noted in the preface to his book of Civil War photographs, "verbal representations of such places, or scenes, may or may not have the merit of accuracy; but photographic presentments of them will be accepted by posterity with an undoubting faith" (Gardner 1959).

James Borchert is Associate Professor of Community Studies and History, University of California, Santa Cruz. He is the author of Alley Life in Washington: Family, Community, Religion, and Folk Life in the City 1850 1970, University of Illinois Press, Urbana, 1980.
Others saw the value of photographic records for the study of history. In 1888 George Francis addressed the American Antiquarian Society on "Photography as an Aid to Local History," urging "the prompt collection in a systematic way" of photographs as "the best possible picturing of our lands, buildings, and our ways of living" (Francis 1888:279, 275). Unlike Gardner, however, Francis demonstrated a sophisticated knowledge of the possible "error caused by bias or prejudice of the operator" (ibid:276). ${ }^{3}$ Nearly 30 years later an English publication, The Camera as Historian, went so far as to argue that photographic sources have "a value greatly outweighing" other historical records (Gower, Jast, and Topley 1916:1). Like Francis's work, this study sought mainly to provide guidelines for local historical societies wishing to carry out systematic visual surveys of material culture and landscape for current and future historical work. Their interest was more in recording and preserving than in the actual use and interpretation of such documents. These studies had a strong influence on the efforts of amateur and professional photographers who sought to record the visual landscape, while at the same time a new breed of documentary photographers, often motivated less by historical concerns than by aesthetic and social ones, focused on social problems. ${ }^{4}$

Professional historians were slower in coming to an appreciation of the potential of photographs for their own work. While the "New History" of the Progressive era (1900-1917) viewed history as "every trace and vestige of everything man has done or thought" (thus helping to establish the intellectual basis for the need for and use of photographic records as primary sources), few if any historians used photos as evidence (Robinson 1965:1). During the 1920s, however, a number of historians became interested in using illustrations to convey information. The work of Arthur Schlesinger, Sr., and Dixon Fox (1927-1948) as editors of the "History of American Life" series and Ralph Henry Gabriel's (1926-1929) work as editor of the Pageant of America, like the illustrative work of economist Roy Stryker for American Economic Life (Tugwell, Monro, and Stryker 1925) and geographer J. Russell Smith for North America (Smith 1925), laid the foundation for the movement toward use of visual records that was to come to fruition in the 1930s and 1940s (Hurley 1972:11-16).

The Depression brought with it a renewed interest in the use of photographs, reflecting changes in the history profession as historians turned to new subjects (the "common man") and new approaches (reflecting in part the urgings of Robinson and other New Historians to view the social sciences as allies). The result of this ferment can be seen in the 1939 American Historical Association convention, which was devoted to the "Cultural Approach to History" (Ware 1940). Along with papers on demography, folklore, folk music, and linguistics, historians heard Roy Stryker (then head of the Historical Division 
of the Farm Security Administration) and Paul Johnstone argue that "photography can easily reach the vast number of human beings whose lives ordinarily are unrecorded either in literary sources or in formal graphic sources" (Stryker and Johnstone 1940:327). While warning of the potential for bias in selection and calling for historians to advise photographers in their work, Stryker and Johnstone also noted that photographs offered a "new means with which the historian can capture important but fugitive items in the social scene" (ibid.). Moreover, they went beyond earlier work to suggest the areas in which photographs could be utilized in historical research; these ranged from the most obvious - recording physical details of material cultureto "clues to social organization and institutional relationships" and interpretation of the "human and particularly the inarticulate elements" (ibid.:329, 330). They went on to contrast a "Michigan Iron Miner's Home" with that of a black "Sharecropper Family" in Louisiana to suggest social organization and institutional relationships, while a Lewis Hine photograph of an "Italian Immigrant Mother and Chiid at Ellis Island" in 1905 "reflected the order, the security, the sense of status, and the personal relationship which characterized the peasant culture from which this immigrant had come" (ibid.:330).

While Stryker and Johnstone offered insights into the possible uses of photographs as primary documents for historical research, they did not elucidate methods for analyzing a large body of photographs or suggest how such information could be readily incorporated into a study. Although they did note that the "photograph cannot ordinarily stand by itself," they left historians to work out their own forms and methods for analysis (ibid: $: 326$ ).

Of course, historians have continued to use photographs, or drawings made from them, for illustrations. Moreover, in recent years certain subfields have employed photographs as research documents. This is especially true in the fields of historical archeology, art history, and material culture. Nevertheless, the photographs used in these studies are generally taken or generated by the particular study; such research does not involve analysis of historical photographs.

A number of recent studies have sought to use photographs as primary documents directly in their analysis. In a 1969 study, Chicago: Growth of a Metropolis, Harold Mayer and Richard Wade claimed that they were breaking historical ground by using "photography as evidence instead of as mere illustration" (Mayer and Wade 1969:1). Although they do include a brief essay on their sources, including a discussion of the limitations and biases, they neither apply nor develop methods for photoanalysis. Their study does, however, provide extensive visual sources that could be subjected to such an analysis. Similarly, a number of recent studies that set out to use "photographs as historical technique and source" carefully apply strict rules of historical evidence to photographs to ensure validity and accuracy; they are designed, however, to "re-create the past" by explaining visual images of it rather than interpreting or analyzing that past (Harney and Troper 1975:x). Other studies draw on information in photographs but attempt no systematic analysis (Daniels $1980: 8-11,55,128,136,171$ ), or they utilize photographs in interviewing to elicit more information (Daniel 1977) or extensively document individual photographs (Rundell 1977). Only one of these studies makes an effort to discuss the methods used, and it is largely a discussion of the application of rules of evidence with no consideration of how analysis proceeds (Rundell 1978). ${ }^{5}$

While historians have continued to use photographs as illustrations, then, they have not used them as sources in any systematic or comprehensive way; they have not elicited data from photographs to develop an interpretive or analytical account. This condition exists despite the growing number of calls by historians for the use of photographic records as primary sources (Morison 1967; Peters and Mergen 1977; McCord 1978; Thomason 1978; Schlereth 1980; Hurley 1981). It is possible, nevertheless, to do analyses of historical photographs, drawing on social science techniques and adapting them to fit the different circumstances that historical photographs present.

This article provides a detailed discussion of the methods, problems, and results of photoanalysis applied to 900 historical photographs as part of a larger social history/community study - Alley Life in Washington from 1850 to 1970 (Borchert 1980). ${ }^{6}$ The research focused on black folk migrants who lived in small dwellings facing on interior alleys (within city blocks) in the core of the nation's capital. It attempted to determine the extent to which these migrants adjusted to their new environment. While photoanalysis was used to uncover patterns in material culture and behavior, the overall study sought "multiple confirmation" through a "multimethod approach" (Webb et al. 1966:5)

First, the methods of collection and a brief description of the photograph compilation that resulted are discussed. Next, the issues of representativeness of the compilation, its validity, and the potential bias resulting from photographer selection are taken up under two sections: Validity and Bias. In conclusion, analysis process and a brief report of the findings are presented, along with comments on the value of historical photoanalysis. 


\section{Collection Methods}

The theoretical base for the collection procedure was developed from E. Richard Sorenson's "Research Film" (1973:3-4; also 1976:247-255) and Jon Wagner's collection strategy (1979:148-152), methods developed by researchers who were producing their own visual records rather than relying on existing ones. Because the historian is seldom able to "take pictures" and because those pictures that remain often lack much information about the content or context of the photograph, it is necessary to adapt these methods (Byers 1966). Most important of these adaptations is the requirement that the largest number of photographs about a given research topic be collected. Photographs from each photographer (or collection) are biased, often in ways that are difficult to determine fully. The more photographs one has to work with, the easier it is to begin to detect bias in an individual's work (or that of an individual collection). Similarly, an entire photograph compilation (all photographs collected on a topic) can be biased; in the case of this study it is most obvious in the absence of any photographs from alley residents themselves (Worth and Adair 1972). However, the greater the size of a compilation, the more likely are the chances for a variety of approaches and emphases (resulting from different photographers' motivations and concerns), and thus a richer "data base" in terms of the "intentionally" recorded images as well as the "unapprehended and unanticipated, incidental surrounding information' (Sorenson and Gajdusek 1963:113) the camera recorded without the photographer's knowledge (Sorenson 1976:248; Wagner 1979:148-149).

\section{Sources of Alley Photographs}

As suggested earlier, no visual records came from the Washington alley population itself. This is largely the result of a currently dispersed population and the very limited resources alley residents had until gentrification altered the nature of the alley population in the late 1940 s and 1950 s. $^{7}$ While the poverty of alley dwellers greatly reduced the likelihood that residents would record their life experiences either in written or visual form, it did ensure that others would. In large part because alley dwellers, like many marginal peoples, were considered a threat and a problem to the city, their activities attracted the interest of a wide range of individuals and organizations.
One of the earliest sources for visual records of alley life is the housing reform movement; numerous reformers took photographs to illustrate lectures and publications. With few exceptions, however, only the prints in publications remain, and these are of poor quality due to the print technology of the period ${ }^{8}$ (see Table 1). While the reform movement represents the major source for photographs in the earliest period (1900-1919) and becomes less important in later years, it is often difficult to separate "reformers" and government agents since they were often interchangeable in either period. Government sources, the most voluminous of those for the study of alley life ( 62 percent of the entire compilation), include the Alley Dwelling Authority Collection (A.D.A.), a national-local agency set up during the New Deal to rid the city of the alley menace (30 percent of all photographs); the Farm Security Administration Collection (F.S.A.), a national agency whose Historical Section visually recorded American society from 1935 to 1942 (15 percent); and the Redevelopment Land Agency Collection (R.L.A.), a local agency set up to implement the redevelopment of southwest Washington in the 1950 s (12 percent). ${ }^{9}$ Newspaper archives (Washington Star, 1930-1955; Daily News, 1941-1957) contributed 6 percent of the total photograph compilation, while another 2 percent came from a variety of sources including an amateur photographer contest on housing conditions in 1947.10 Finally, I made several surveys of alley housing in 1970 and 1972 ( 17 percent). ${ }^{11}$

Clearly not every possible source of photographs on alley life was utilized; some were not accessible while others undoubtedly remain to be discovered. Nevertheless, the compilation includes 747 historical photographs with an additional 151 photographs in the 1970s for comparison. ${ }^{12}$

\section{Methodology}

While one can take only written notes on photographs in Archives as the basis for analysis, ordering only those prints to be used for publication (Rundell 1978:390), that approach was quickly abandoned for this study. Because it is difficult to know just what is important in the photograph compilation and because notes on photographs greatly limit re-analysis of photographs for new evidence, I decided to make copies of all archival photographs. When prints were available in archives (or other sources), I copied these photographs using a hand-held 35-mm SLR camera (or copy stand when possible). For very small photographs, I used extension tubes; for pictures that had important data requiring "enlarging," I made close-up copies as well as recording the entire picture to avoid loss of context. (The close-ups were later enlarged to facilitate further analysis, but the enlargements were always accompanied by the entire picture so that the analysis did not remove them from 


\section{Table 1 \\ Distribution of Photographic Compilation by Photographer Organization and Time Period.}

\begin{tabular}{|c|c|c|c|c|c|}
\hline $\begin{array}{l}\text { Photographer } \\
\text { Organization }\end{array}$ & $\begin{array}{l}\text { Time Period } \\
1900-1919\end{array}$ & $1920-1949$ & $1950-1961$ & 1970-1972 & Total \\
\hline Reform & 82 & 15 & 19 & & $116(13 \%)$ \\
\hline Official & 32 & 423 & 104 & & $559(62 \%)$ \\
\hline Professional & & 2 & 6 & & $8(1 \%)$ \\
\hline Newspaper & & 51 & & & $51(6 \%)$ \\
\hline Amateur, other & 5 & 8 & & & $13(1 \%)$ \\
\hline Author survey & & & & 151 & $151(17 \%)$ \\
\hline Total & $119(13 \%)$ & $499(56 \%)$ & $129(14 \%)$ & $151(17 \%)$ & $898(100 \%)$ \\
\hline
\end{tabular}

the already limited visual context.) When only negatives were available in archives, I ordered copies made from them.

At the same time that I copied the prints, I also made complete notes on the photographs being copied as well as on their context. Information specific to each photograph was recorded by frame and roll to facilitate matching them up with prints. ${ }^{13} \mid$ then had the film processed commercially and had three proof sheets (contact prints of the negatives) made for each roll. The first set of contact sheets are stored (as the original "research film collection") with the negatives and the original notes for each print (Sorenson 1973).

The other two sets of proof sheets were cut up into individual frames. Each print was mounted on a 5-by-8inch card (an original and a duplicate) containing the source of the photograph, archival order number or page number (if from a publication), date, agency responsible for the photograph, photographer, location where the photograph was taken, and the caption (when this information was available) (Collier 1979:167). In some cases I made notes on the cards of photographs that were taken in sequence so that a larger context could be established in the analysis. ${ }^{14}$ Finally, these cards were assembled by collection, individually numbered but in a running sequence for the entire compilation; this segment of the data collection is called the Card File.

The Card File represents an important tool in the initial stages of analysis. The data on the card were used to set up three indexes: an index of alley locations, an index of alley photographers, and a content index. The latter lists photographs by their cornpilation number for type (aerial, raised view, etc.); subject (alley view, alley house, backyard, interior, etc.); presence of adults and children; and a complete inventory of material culture. Because the $35-\mathrm{mm}$ prints on the card are small and of varying quality, the index constructed from them is not as complete or accurate as it might be: for example, not all material culture is identifiable in these prints, nor are all interactions. Nevertheless, this index provides the first step in the analysis process because it permits the sorting of enlargements into different categories (nearly always multiple) for analysis of particular aspects of life. ${ }^{15}$

As suggested above, the final photoanalysis was made on 8-by-10-inch enlargements of the prints in the compilation. To facilitate this, I made study enlargements of nearly 500 of the total 898 photographs; prints from archival sources bring the total of enlargements to about 600 and together make up the Print File. ${ }^{16}$

To supplement the Card File I constructed a Catalog, which aggregates data on each collection from the number of prints to the subject of the photographs as well as recording all general information about the collection. Data from each collection were then aggregated to provide a clearer sense of the entire compilation. Finally, after completion of the analysis, copies of the Catalog, Card File, Index, and Print File were donated to an archive so that all materials could be used by other researchers. ${ }^{17}$ 


\section{Description of the Compilation}

Information from the Catalog and the indexes provides a general description of the photograph compilation. As is apparent from Table 2, more than a half lack the photographer's name, and a quarter lack a location. In the case of missing information on the date, most photographs can be attributed to a general time period if not to a given year. While photographers' names are most likely to be absent from the captions, it is possible occasionally to find the names of the employee(s) responsible for some photographic work, although it is impossible to know which photographs they took. Finally, while the most complete information exists on location, some caution is necessary. As Rundell found (1978: 394-396), captions are not always accurate, and this proved to be the case for at least some of the alley photographs. This misinformation was easiest to spot in cases of well-photographed alleys or those with wellknown landmarks. For many photographs, however, insufficient information made it impossible to affirm the accuracy of the caption.

The vast majority of photographs ( 87 percent) are exterior views of either the alley, the houses, the backyard or various combinations of these. Only 9 percent of the views are interiors, while aerial views, drawings based on photographs, portraits, and photographs of alley children at work outside the alley provide even fewer images for analysis.

\section{Validity}

The preceding discussion of the data available on the photographs and the disproportionate emphasis on exterior views suggests some limits on the compilation. It was necessary to submit the compilation to systematic analysis to determine more fully the extent to which it is representative of alley life. The entire set of photographs was evaluated to determine their distribution by time period, numerical distribution (concentration on large or small alleys), and spatial distribution (concentration on specific areas of the city).

\section{Distribution by Time Period}

Photographs in the compilation disproportionately represent the later time periods. Table 2 shows clearly that, although alley housing began in the 1850 s and reached its peak just prior to the turn of the century, no known photograph was taken prior to $1900 .{ }^{18}$ Moreover, only 13 percent of the compilation comes from the period 1900-1919; the vast majority ( 56 percent) comes from the period 1920-1949, although few photographs were taken in the 1920s. Finally, 14 percent of the photographs comes from the transition period of the 1950 s as the remaining dwellings were either torn down or renovated for the middle class; the collection from the 1970s demonstrates the end product of this process. Unfortunately, the larger study suffered from this chronological imbalance of sources. Since the research emphasis was concerned with the general patterns of life rather than change in alley life, this imbalance was less critical. Though tracing change is greatly inhibited by the skewed distribution, it is nonetheless possible to detect change over time in the material culture, use of alley space, and physical conditions of houses.

\section{Table 2}

\section{Description of Photographic Compilation}

\begin{tabular}{lccccccccccc}
$\begin{array}{l}\text { Time } \\
\text { Period }\end{array}$ & $\begin{array}{c}\text { Number } \\
\text { of } \\
\text { photos }\end{array}$ & $\begin{array}{c}\text { Number } \\
\text { with } \\
\text { date }\end{array}$ & $\begin{array}{c}\text { Number } \\
\text { with name: } \\
\text { photographer }\end{array}$ & $\begin{array}{c}\text { Number } \\
\text { with } \\
\text { location }\end{array}$ & \multicolumn{2}{c}{$\begin{array}{c}\text { Subject of Photograph } \\
\text { Exterior }\end{array}$} & Interior & Aerial & Draw & Portrait & Work \\
\hline $1900-1919$ & 119 & $9(8 \%)$ & $52(44 \%)$ & $82(69 \%)$ & $100(84 \%)$ & $4(3 \%)$ & 0 & 0 & $6(5 \%)$ & $9(8 \%)$ \\
\hline $1920-1949$ & 499 & $389(78 \%)$ & $170(34 \%)$ & $324(65 \%)$ & $417(84 \%)$ & $58(12 \%)$ & $14(3 \%)$ & $3(-)$ & $7(1 \%)$ & 0 \\
\hline $1950-1961$ & 129 & $14(11 \%)$ & 0 & $119(92 \%)$ & $113(88 \%)$ & $16(12 \%)$ & 0 & 0 & 0 & 0 \\
\hline $1970-1972$ & 151 & $151(100 \%)$ & $151(100 \%)$ & $151(100 \%)$ & $151(100 \%)$ & 0 & 0 & 0 & 0 & 0 \\
\hline Total & 898 & $563(63 \%)$ & $373(42 \%)$ & $676(75 \%)$ & $781(87 \%)$ & $78(9 \%)$ & $14(2 \%)$ & $3(-)$ & $13(1 \%)$ & $9(1 \%)$
\end{tabular}


* There are photographs of 14 other alley blocks that are not included here because they fall outside the "Federal City" area or because they were not enumerated in the 1897 police census.

tCommissioners of the District of Columbia, Annual Report-1897 (Washington, 1897), pp. 195-202. Data compared here are not directly comparable. The data base of 1897 predates any of the photographs, and the size of alley blocks and the alley population diminished as the twentieth century advanced. Ideally, each photograph should be compared to the distribution of alley blocks and population in the year in which it was taken; however, since this information is not available, the use of the 1897 data base is meant to be suggestive of the reliability and areas of possible bias in the photograph compilation.

\section{Table 3}

\section{Alley Block Density and Alley Population Total Compared to Photograph Distribution in 1897}

Alley Block Population

\begin{tabular}{lccccc} 
& $1-99$ & $100-199$ & $200-299$ & $300-399$ & Over 400 \\
\hline $\mathbf{1 ~ N o . ~ o f ~ b l o c k s ~ ( 1 8 9 7 ) ~}$ & $194(75 \%)$ & $44(17 \%)$ & $16(6 \%)$ & $4(2 \%)$ & $1(-)$ \\
\hline $\begin{array}{l}\text { 2 No. of blocks } \\
\text { photographed with } \\
\text { population size }\end{array}$ & $36(51 \%)$ & $21(30 \%)$ & $9(13 \%)$ & $4(6 \%)$ & \\
\hline $\begin{array}{l}\text { 2-1 Difference in percent } \\
\text { of distribution }\end{array}$ & $-24 \%$ & $+13 \%$ & $+7 \%$ & $+4 \%$ & $-1 \%$ \\
\hline
\end{tabular}

Alley Population Density

\begin{tabular}{cccccc} 
& $1-99$ & $100-199$ & $200-299$ & $300-399$ & Over 400 \\
\hline 1 Alley population (1897) & $6923(36 \%)$ & $6204(33 \%)$ & $4026(21 \%)$ & $1356(7 \%)$ & $469(3 \%)$ \\
\hline
\end{tabular}

2 No. of photographs

of blocks with

population size $\dagger$

$164(31 \%) \quad 103(20 \%) \quad 170(33 \%) \quad 84(16 \%)$

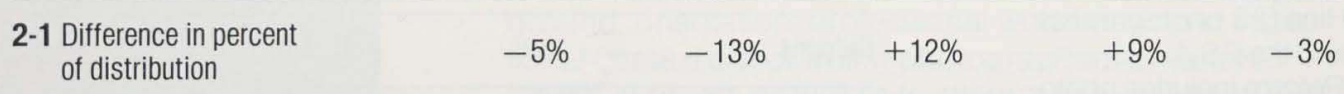

\section{Numerical Distribution}

It is clear from Table 3 that the compilation overrepresents larger alley blocks; while nearly 70 percent of alley residents in 1897 lived in alleys smaller than 200 people, only 51 percent of the photographs were taken in alleys of that size. As the note for Table 3 indicates, however, these figures are not directly comparable since the alley population dropped off considerably as the twentieth century advanced. Nevertheless, this concentration on alleys that had the largest populations, those that were considered by observers of alley life to be the most disorganized and disorderly, rather than on the smaller alleys that contained a larger proportion of the alley population does represent a bias in the compilation (Ratigan 1941:118-119). 


\section{Table 4 \\ Spatial Distribution of Alley Population and Photographs}

\begin{tabular}{llll}
$\begin{array}{l}\text { Section } \\
\text { of city }\end{array}$ & $\begin{array}{l}\text { 1897 alley } \\
\text { blocks }\end{array}$ & $\begin{array}{l}\text { Photographed } \\
\text { alleys }\end{array}$ & $\begin{array}{l}\text { Photographs by } \\
\text { alley }\end{array}$ \\
\hline Northwest & $135(57 \%)$ & $29(41 \%)$ & $198(38 \%)$ \\
\hline Southwest & $60(25 \%)$ & $25(36 \%)$ & $160(31 \%)$ \\
\hline Northeast & $23(10 \%)$ & $9(13 \%)$ & $86(16 \%)$ \\
\hline Southeast & $19(8 \%)$ & $7(10 \%)$ & $77(15 \%)$ \\
\hline Total & 237 & 70 & 521
\end{tabular}

*Documentary here includes the work of Lewis Hine (23 photographs) and the F.S.A.

tReform includes photographs from Charities/ Charities and the Commons/Survey and Weller (1909), but not Hine's work for these studies.

¥Washington Star (36) and Washington Daily News (10).

§Government agency includes the A.D.A. and the R.L.A.

\section{Table 5}

Juxtaposition of Alleys to Monumental Buildings as a Motif

\begin{tabular}{|c|c|c|c|c|c|c|}
\hline $\begin{array}{l}\text { Photographic } \\
\text { style }\end{array}$ & $\begin{array}{l}\text { Number of } \\
\text { photographs }\end{array}$ & $\begin{array}{l}\text { Monumental } \\
\text { building in } \\
\text { photograph }\end{array}$ & $\begin{array}{l}\text { Monumental } \\
\text { building in } \\
\text { caption }\end{array}$ & $\begin{array}{l}\text { Monumental } \\
\text { building in } \\
\text { both }\end{array}$ & Total & Percent \\
\hline Documentary* & 155 & 7 & 29 & 21 & 57 & $37 \%$ \\
\hline Reform† & 59 & 0 & 3 & 2 & 5 & 8 \\
\hline Photojournalists $\ddagger$ & 46 & 0 & 4 & 4 & 8 & 17 \\
\hline $\begin{array}{c}\text { Government } \\
\text { agency§ }\end{array}$ & 369 & 10 & 5 & 16 & 31 & 8 \\
\hline Total & 629 & 17 & 41 & 43 & 101 & $16 \%$ \\
\hline
\end{tabular}

\section{Spatial Distribution}

Ironically, while the largest alleys (and the largest number of alleys -57 percent) were located in the Northwest section of the city (and secondarily in the Southwest section), the photograph compilation tends to overrepresent the other three quadrants of the city. Part of this bias reflects the specific mandates of agencies that made photographic records; the R.L.A. initially focused on redevelopment of the Southwest, while others (documentary photographers) concentrated on alleys located around Capitol Hill. It is not clear what impact this bias has on the compilation, except that the area of major alley housing is underrepresented (see Table 4). 
The attraction that the Capitol Hill area held for documentary photographers does provide some interesting insight into both the skewed spatial distribution of photographs and bias in selection. While part of the attraction probably had to do with these photographers' limited knowledge of the city and concern for their safety and convenience, it is also clear that one of the formulas for documentary photographers was to juxtapose the crowded and slum areas in the foreground with some part of monumental Washington in the background (see Table 5). The Capitol's high visibility made it a popular target for these photographers (see Figure 1), while other massive buildings or city landmarks (see Figure 2) also served as subjects to contrast.

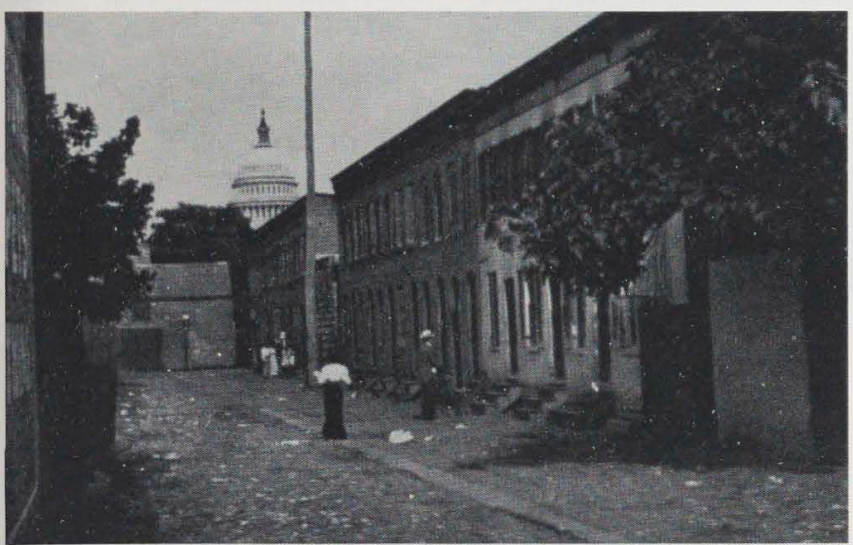

Figure 1 Louse Alley, with the Capitol dome, in contrast, three blocks away. It portrays "crowded lodgings of Italian laborers adjoining colored bawdy houses." 1908. Lewis W. Hine. (From Charles Weller, Neglected Neighbors, 1909)

\section{Bias in Selection}

While skewed distributions of photographs by time period as well as numerical and spatial categories represent important limits in the compilation, it is equally as important to attempt to determine the extent and nature of bias that results from the photographers' selection process. The decision-making process that determines what a photographer will record and will not record is perhaps the most difficult and tortuous to unravel. Rather than analyze each photographer, however, it is possible to consider them by genre or style. As Table 5 seems to suggest, photographers in a given field tend to share similar views as to what is important; their work reflects their socialization, training, and institutional affiliation. Barbara Rosenblum (1978:1-2) has found that work organization, among other influences, "affects style. Certain distinctive social processes dominate each setting where pictures are made and they affect what photographers can and cannot do, what kinds of images they can and cannot make, what kinds of visual data they can include in the pictures or leave out" (see also Becker 1974a:767-776; 1978:9). In addition, there is the real danger of intentional distortion; a recent study of historical photographs of North American Indians revealed that nineteenth-century photographers "posed the Indians in costumes not their own, and then retouched the negatives" (Scherer 1975b:67-79).

It is necessary, then, to attempt to reconstruct the background, orientation, professional world view, and institutional context out of which photographers of various "styles" worked, as well as to attempt to reconstruct the context of the actual photographing assignment, to determine the various selection processes operating. The work of documentary photographers (Lewis Hine and the F.S.A.) is treated more fully because there is a substantial body of information from which to work. The others - the reform movement, photojournalists, and government agency photographers - are often anonymous or nearly so; their visual record is the most available source for insight.

\section{Documentary Photographers}

Lewis Hine (1874-1940), who certainly ranks as the dean of American documentary photography, began photographing in conjunction with his teaching at the Ethical Culture School in New York City in 1903. Between 1906 and 1908, Hine went to Washington to provide illustrations for Weller's (1909) study, Neglected Neighbors (Weller was the executive officer of Associated Charities, 1901-1908); fifteen of Hine's alley photographs appeared in that volume. He photographed for a number of charity and reform groups before beginning a longtime "attachment" to Charities/Charities and the Commons/Survey. He also worked for the National Child Labor Committee, for which he made nine photographs 


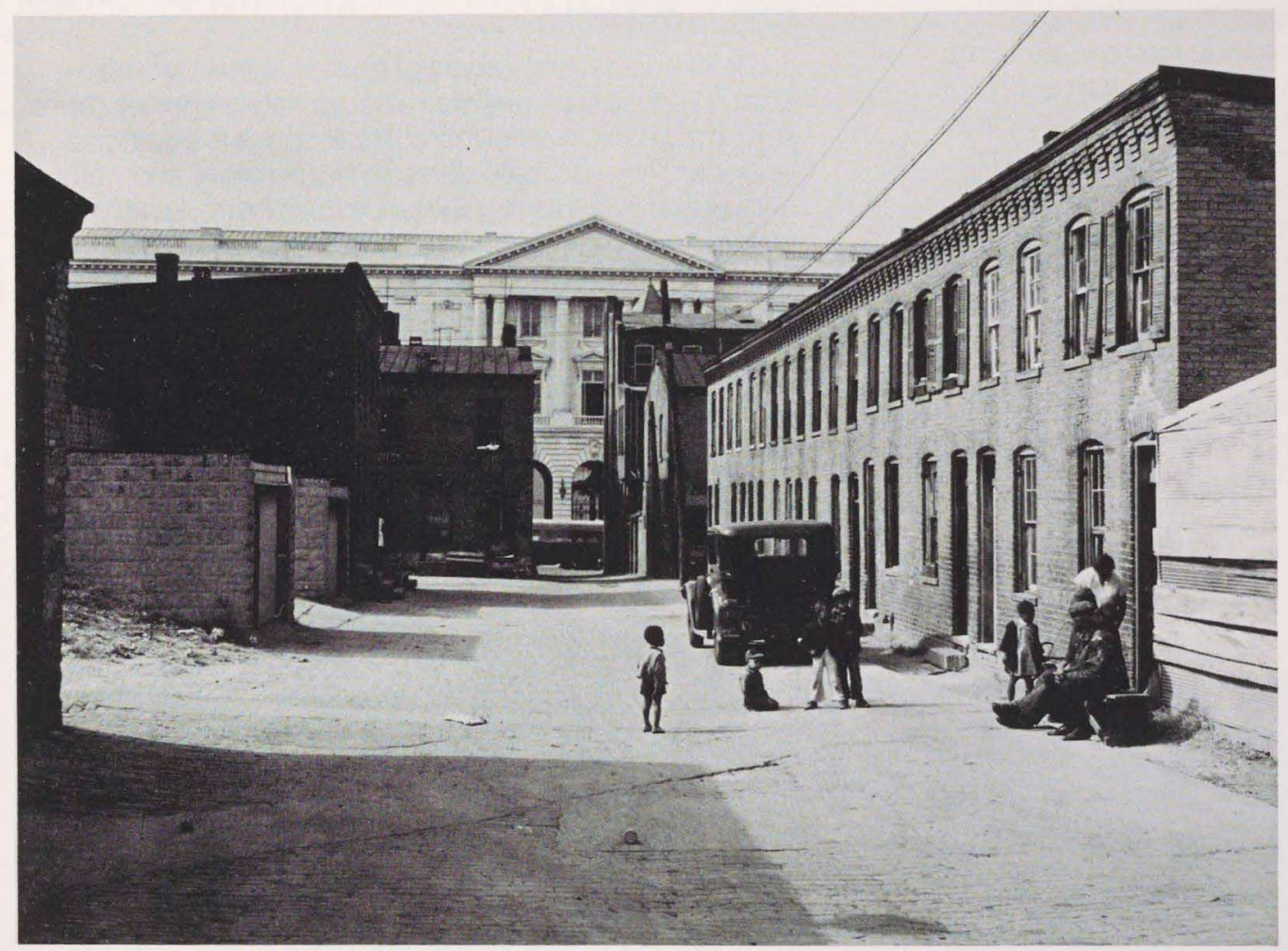

Figure 2 Schotts Alley, with Senate Office Building in the background. Four very small rooms rent for $\$ 15$ and $\$ 18$ a month with water and privy in backyard. It used to rent for $\$ 6$ and $\$ 8$. Frank Coles and his friend are sitting on the bench. He was a cement plasterer but has been on relief for the past year. He has frequent heart attacks and swollen feet and ankles. September 1941. Marion Post Wolcott. (Farm Security Administration Collection, Library of Congress)

recording alley children at work as newsies and vegetable vendors on Washington streets in April 1912 (Gutman 1967).

Hine worked with a 5-by-7-inch view camera and a "shaky tripod"; the process was, he noted, "slow as molasses" (Hine 1938). This condition meant that Hine had to negotiate for approval for many of his close-up or portrait photographs; later documentary photographers who used $35-\mathrm{mm}$ cameras had greater flexibility in this regard. Writing in 1938, Hine recalled his concern for truthfulness: "all along, I had to be doubly sure that my photo-data was 100 percent pure, no retouching or fakery of any kind" (ibid.). He also noted that his goal had been "to show the things that had to be corrected. to show the things that had to be appreciated" (Marks 1939:157).

Weller may have accompanied Hine on a photographing tour of the Washington alleys and slums. Virtually all the Hine photographs from this tour are views looking down a long narrow alley lined on either side with houses (see Figure 3); some contrasted the alley with the Capitol in the background (see Figure 1). All were taken during the day; there are no interior shots; and for the most part those who appear in the background (residents?) seem unconcerned and "natural." There are none of Hine's famous "Madonna and Child" photographs here, and Purdy's Court (Figure 4) is one of the few where there is a clear interaction between photographer and "subject"

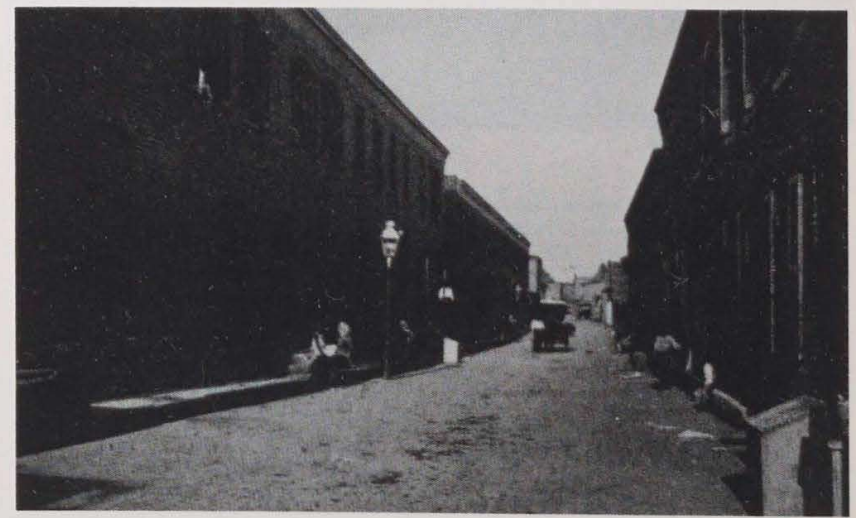

Figure 3 Tenements, at left, in Logan Court, an interior alley. 1908. Lewis W. Hine. (From Charles Weller, Neglected Neighbors, 1909) 
(posed and smiling), a photograph that seems to contradict one of the themes of the book it illustrated. The nine photographs made for the National Child Labor Com mittee are nearly all posed with important buildings in the background.

While Hine never worked for the Historical Section of the F.S.A., it is clear that his work greatly influenced director Roy Stryker and the photographers who worked for the agency from 1935 to 1942. Stryker, who came to the F.S.A. after working as a lecturer in economics at Columbia University, was not a photographer. Moreover, while his section was probably intended to provide publicity photographs for the F.S.A., Stryker saw the task in broader terms and expanded the goal of the agency to visually record America, although the emphasis was always on rural areas.

Like Hine, Stryker was motivated by a complex set of concerns; on the one hand he wanted to record American life as it was: "I wanted to do the story of a farmer doing something" (Stryker 1964a:44). Like much of Hine's work, Stryker's also was committed to photographs that show "respect for the human being" (Stryker 1964b:12) as well as to "a policy of total truthfulness" (Hurley 1972:ix). Nevertheless, both Stryker and the F.S.A. photographers destroyed negatives they felt were no longer useful or were of poor quality (Stryker 1965:7-8; Rothstein 1979:8)

Because most F.S.A. photographers joined the section with at least some experience and because Stryker was not a photographer, there was little technical instruction or guidance on composition save for that which came from colleagues. ${ }^{19}$ Stryker was concerned with the content of photographs and "operated the photograph section more like a seminar in an educational institution" (Rothstein 1979:7). He assigned books for photographers to read before assignments and had long talks with them prior to leaving. While in the field photographers made contact with F.S.A. employees or other experts to guide their work. In addition, Stryker carried on a rich correspondence with photographers in the field, praising completed work, giving detailed instructions for the kinds of photographs needed by the section, urging more complete captions, and critiquing work in terms of content (Stryker 1935-1943). Eventually he developed shooting scripts to guide photographers in the field, but these were never mandatory and photographers continued to work at their own discretion (ibid.; Stryker 1965:33-34; Wolcott 1965:9-10).

While a substantial number of F.S.A. photographers visited and visually recorded alley conditions in Washington, these photographs represent a tiny fraction of the agency's work; no visit represented a major effort, and there is no correspondence or shooting scripts associated with these assignments. Similarly, the photographers remember little about these visits (Wolcott 1981; Mydans 1981). Unlike Hine, the F.S.A. photographers do not seem to have had any guides or expert resource people to help them, nor were there any

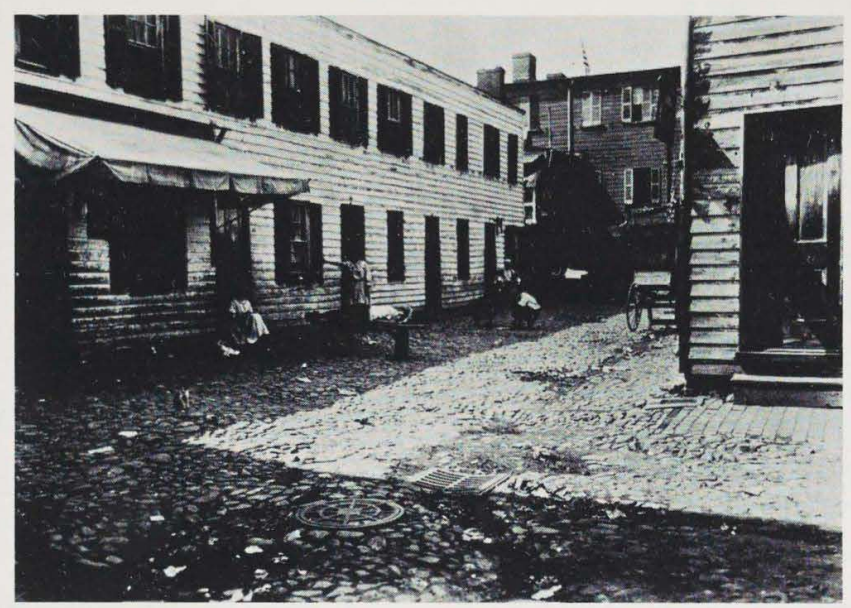

Figure 4 Purdy's Court NW: a back alley near the Capitol grounds. 1908. Lewis W. Hine. (Lewis Wickes Hine Collection, George Eastman House, Rochester, N.Y.)

books assigned prior to the photographing assignment (Wolcott 1981).

While F.S.A. photographers used $35-\mathrm{mm}$ cameras instead of the more cumbersome large-format view cameras of earlier documentary photographers, few prints clearly reflect their use to "capture" alley residents with candid shots (see Figure 5). There are a large number of long views of alleys in which residents appear relaxed and unconcerned by the presence of the photographer. Most striking are the large numbers of portraits, "posed" photographs, close-ups of alley dwellers, and interior views; all required some kind of approval from the subjects (see Figures 6, 7, 20, 23, 28 , $30,31,32,40,41$, and 44). Virtually all the photographs were taken during the day, most probably during "working hours," thus limiting the range of activity available

Like Hine's work, then, that of the F.S.A. photographers was limited by their lack of knowledge of alley life and by the time constraints imposed by their position. ${ }^{20}$ Equally as important is the problem of access. Access to social situations varies with the role of the person and the situation (Spradley 1980:47-48); like field workers who are just beginning their study, photog raphers lacked access to the inner world of alley life. If they could "negotiate" for portraits and access to interiors of some homes, they were never close enough to be trusted to see or record alley rites and ritual. As Howard Becker has noted, "a photograph records...the relation of the photographer to the people in the picture, whether that be intimate, friendly, hostile, or voyeuristic. Part of our concern is always to know how much time the photographer spent; we trust the sample more if we know it was a long time. A week is one thing, a year or two or ten is something else" (Becker 1978:12). To these limits to selection must be added the agency requirement to show respect for "subjects" 21 and a series of personal conventions photographers took with them into the alleys: what was appropriate to photograph given the context and what they felt comfortable negotiating for (Stryker 1965:12). 


\section{Reform Photographers}

The turn-of-the-century Washington housing reform movement relied heavily on photographs and lantern slides to get their story across. In addition to bringing photographers like Jacob Riis and Hine to the city, a number of reformers like Weller took up cameras and used their photographs to illustrate their publications, especially those in Charities/Charities and the Commons/Survey.

For the most part these photographers concentrated on the worst housing conditions reformers could find; since their knowledge of alley conditions was substantially greater than that of the unguided F.S.A. photographers, they could document quite terrible circumstances. They also used posed pictures like those by Weller which show an alley dweller drinking whiskey out of a large jug and a row of empty gin bottles lined up on a fence for a photograph (Weller 1909:276, 289). ${ }^{22}$ Captions often had to carry the interpretive load for poorly conceived and printed photographs, and often interpreted pejoratively the behavior or morality of residents who appear in the pictures (see Figure 8). Finally, there are a number of "human interest" photographs of people the captions tell us are "dying of cancer" or are "stricken with paralysis."

If the work of reform photographers provides a balance to that of documentary photographers in terms of their greater knowledge of alley life and their greater concentration on the worst conditions, it nevertheless falls far short of the ideal. Reform photographers took few interior shots and limited their outdoor work to the daylight hours. More importantly, if the documentary photographers were informed by too little theory and a concern not to degrade their subjects, reformers were too informed by inadequate theory and sought to impose it through careful selection, posed photographs, or suggestive captions (Borchert 1980:246-268).

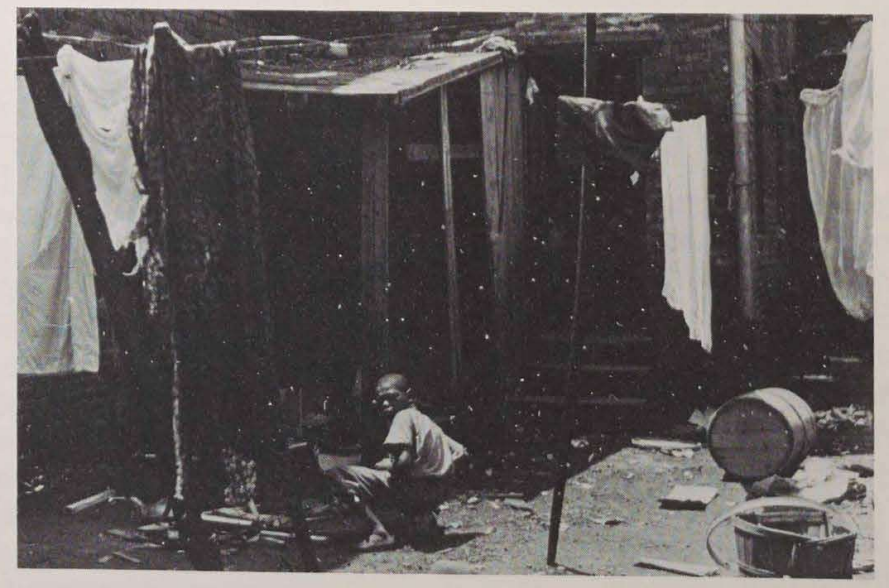

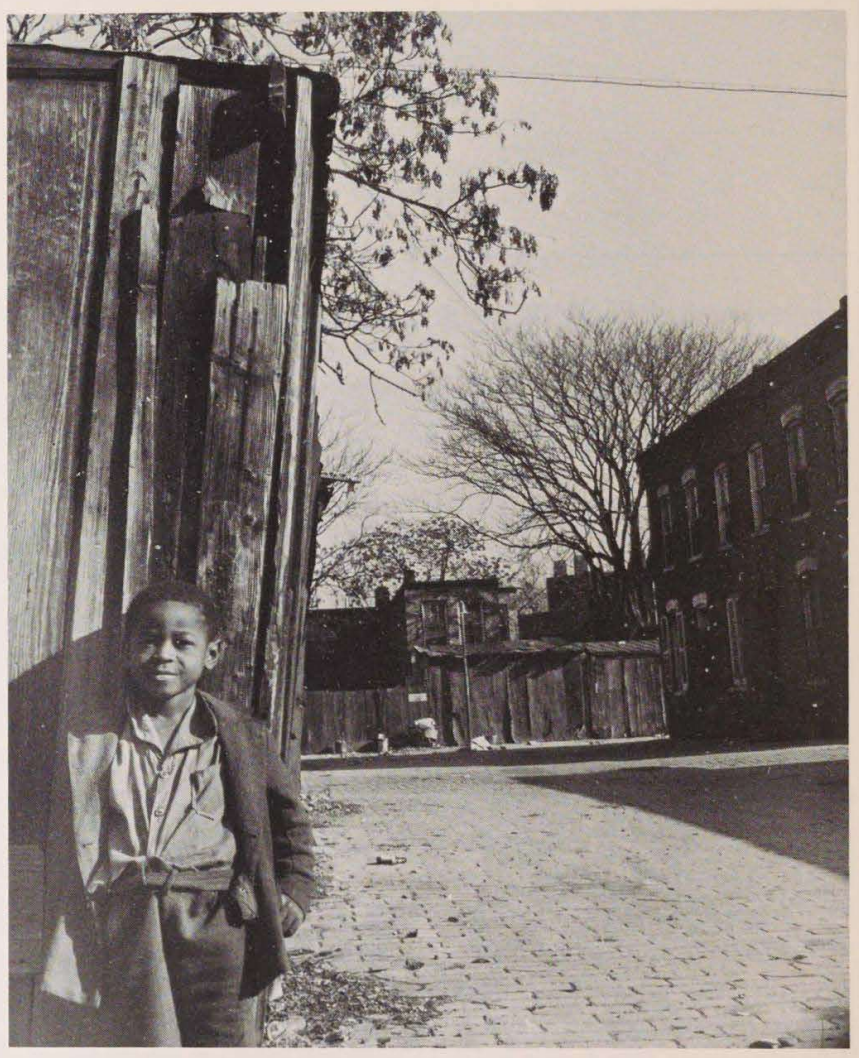

Figure 6 An alley in Southwest Washington. November 1942. Gordon Parks. (Farm Security Administration Collection, Library of Congress)

Figure 5 Backyard near the Capitol. Children have just discovered the cameraman and are concerned at his presence. September 1935. Carl Mydans. (Farm Security Administration Collection, Library of Congress)

Occasionally photographers were not permitted access to communities, or had difficulty photographing some aspects of community life during their travels for the Farm Security Administration (Wolcott 1965). 


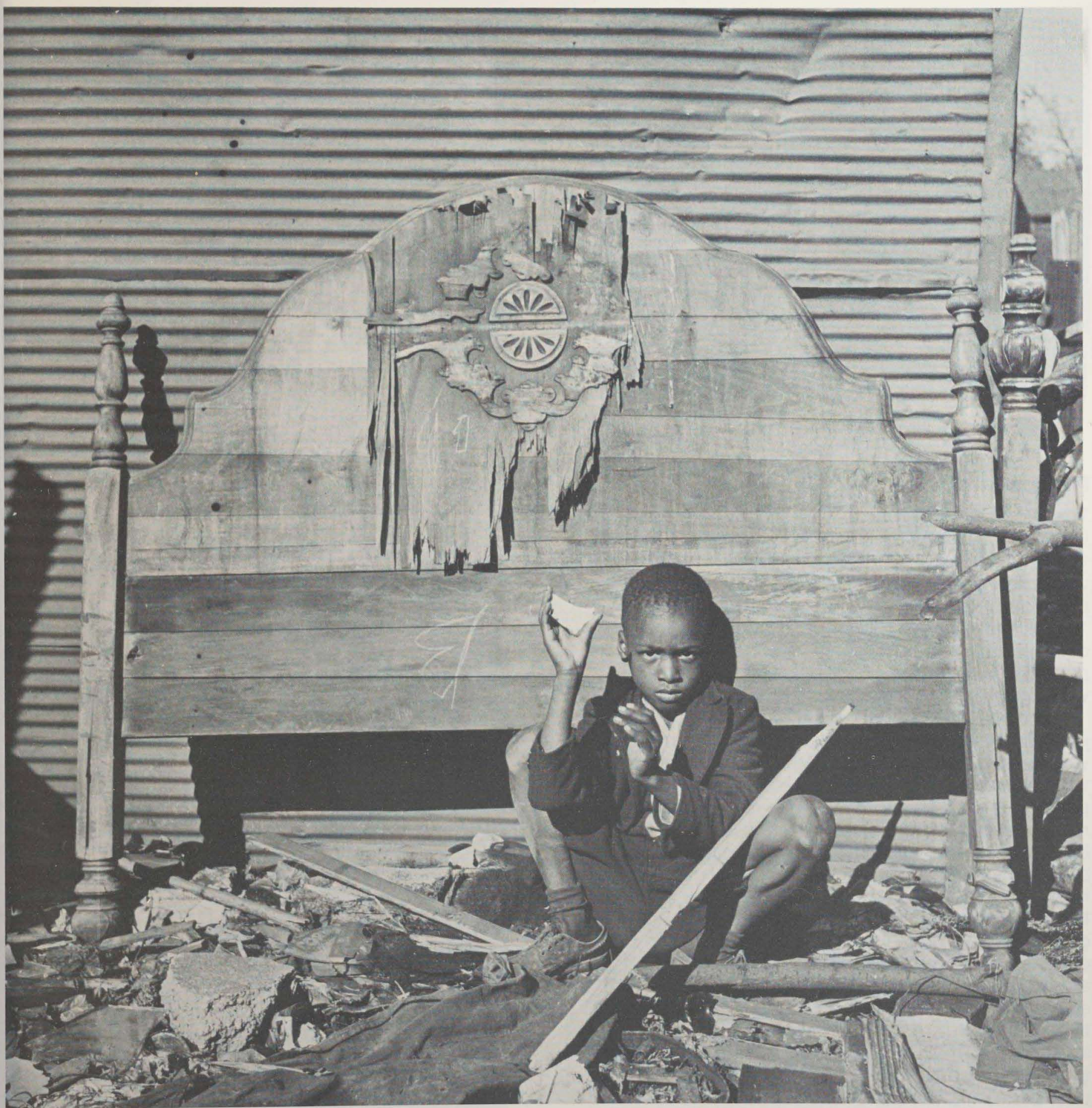

Figure 7 A child whose

home is an alley dwelling

near the Capitol. July

1943. Esther Bubley.

(Farm Security Administra-

tion Collection, Library of

Congress) 


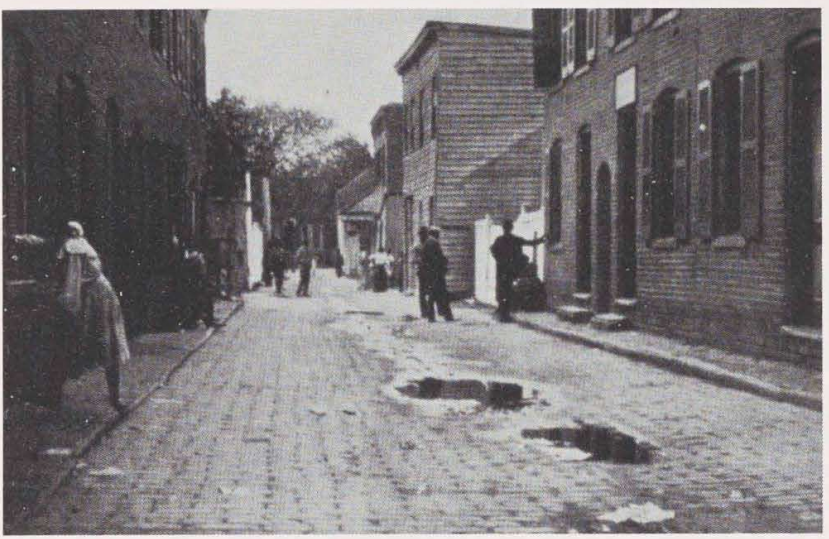

Figure 8 Typical alley vista, part of Ball Alley NW, with the usual midday loafers. 1908. Charles Weller. (From Charles Weller, Neglected Neighbors, 1909)

\section{Photojournalists}

The photojournalists whose work is considered here worked for either the Washington Daily News (19411957) or the Star (1930-1955). Unlike the more diverse work experience and training of other photographers, photojournalists now (and presumably from 1930 to 1957) underwent an "apprentice" experience followed by continuous working relationships with other newspaper photographers, a condition that tends to make their work more uniform (Rosenblum 1978:19-25, 41-62).

In contrast to most F.S.A. photographers, newspaper journalists used large-format cameras, although their work was also done during daylight hours, and probably working hours as well. As Table 4 indicates, newspaper photographers were more likely than reform and government agency photographers to juxtapose monumental buildings or Washington landmarks in their work, although less frequently than documentary photographers. As one would suspect, photojournalists tended to go where "stories" were: 17 percent of the photographs feature important public officials inspecting alley conditions, while others focus on the "reconstruction" of alley houses that led to gentrification or human interest stories that picture bad housing conditions (see Figure 9). In addition there are a number of photographs that are less typical: alley views and the only examples of photographs that clearly depict juvenile delinquency (fighting and vandalism). While photojournalists spent as little time gathering visual records and were no better informed on alley life than the F.S.A., they were not used to negotiating to take pictures and were trained to take action shots of aberrant behavior; and they did not have a compunction against showing people in a bad light. This latter group of pictures, however, makes up only 7 percent of the small collection of prints from photojournalists.

\section{Government Agency Photographers}

While the photographs taken by employees of government agencies make up the largest collections of photographs considered here, very little is known about these photographers; less than 5 percent of the 369 photographs carry a photographer's name, and most of these come from other sources. By contrast, 94 percent of these photographs list the location, although the captions seldom go beyond simply naming the alley pictured.

As with photographers of other collections, official photographers only visited the alleys during daylight hours and apparently only on weekdays during normal working hours. Shadows in Figure 10 do reveal both late-afternoon shooting and the presence of the largeformat cameras used by A.D.A. photographers. While the A.D.A. collection is made up of prints of fairly high quality (made from 8-by-10-inch negatives), suggesting professional photographers from the start, the R.L.A. collection began when an employee in graphics decided on his own to record agency properties apparently for

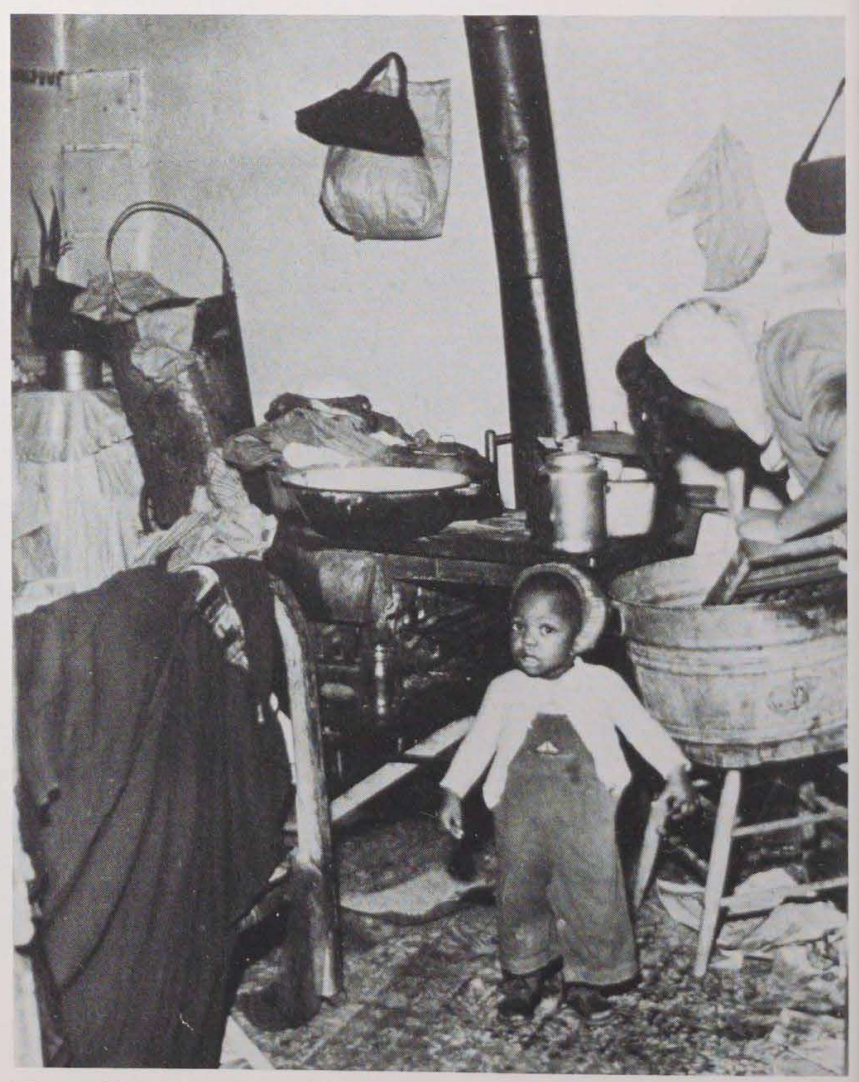

Figure 9 "Cynthia." December 15, 1954. Washington Daily News. (Washingtoniana Collection, Martin Luther King Memorial Library, Washington, D.C.) 
both historical reasons and to demonstrate the work of the agency through before-after photographs. Although he started with a Brownie camera, much of the later work is $35-\mathrm{mm}$ and of better quality.

Unlike the other groups of photographers, save perhaps the reformers, government agency photographers had access to the alleys and individual houses through their agencies, which were concerned with either the renovation or removal of alley housing. Thus, whether alley residents liked it or not-and there is no visual evidence of the latter-agency photographers recorded conditions in the alley in more complete and systematic ways than with any other visual survey. While this involved photographing the physical destruction or renovation in some cases, much work was devoted to recording the physical alley and dwelling, and incidently the alley landscape before this took place. Ironically, while agency photographers had greater access and more time to visit the alleys consistently, there is a relatively small number of interior photographs (11 percent), and many of these were taken after residents moved out (see Figures 11 and 12). Finally, because their connection was with an agency concerned with the removal of bad housing conditions, these photographers focused primarily on the physical conditions (especially R.L.A.), and secondarily on the residents' relationship to these physical conditions (especially A.D.A.).

There is considerable difference, then, between the philosophy and work of the four groups of photographers. While documentary photographers emphasized the strength of the human condition in difficult circumstances and also recorded the physical alley conditions, reformers focused closely on both physical and human pathologies; photojournalists pursued alley stories from Congressional visits and renovations to crime and disorder; and government agency photographers recorded the physical conditions of alleys on the verge of demolition. While this clearly meets Jon Wagner's advice to use several photographers as a strategy for "avoiding error" (Wagner 1979:148-149), it is also quite clear that there is much we cannot learn from these collections of alley photographs largely because certain subjects fall outside the scope of these photographic agendas. Table 6 suggests the areas of alley life for which little or no visual information exists. While at least partial information is present in other kinds of sources about these aspects of life, and while a few photographs do touch on some of these areas, the vast majority do not.

Given the length and depth of this list, it might seem pointless to continue further analysis. Clearly the agendas of diverse groups of photographers who lack a longterm field study commitment to a subject result in a selection process (intentionally or not) that leaves out much that is important. Nevertheless, there are some areas where these agendas have recorded substantial visual evidence that is useful for understanding and interpreting alley life.

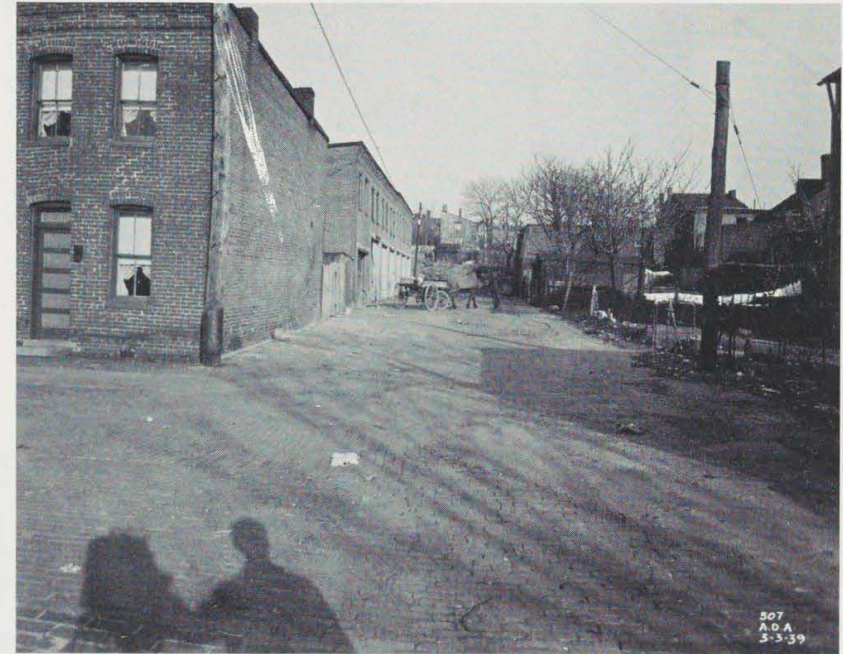

Figure 10 Navy Place SE. March 3, 1939. Alley Dwelling Authority. (Library, Department of Housing and Community Development, Washington, D.C.)

\section{Final Analysis and Findings}

The final analysis process utilized the Content Index to sort photographs into categories for study. The categories chosen reflect the concerns of the larger study: (1) context, setting, and material culture; (2) behavioral landscape; (3) childhood; and (4) other. Within each category each photograph was "inventoried" for specific information, and in most cases a given photograph would be analyzed in several or more areas ${ }^{23}$ It is important to note that these categories are not the only ones that could be used to analyze the compilation.

\section{Context, Setting, and Material Culture}

Photographs provide the best source for establishing the physical context and setting for a study site. While maps, and especially fire insurance atlases for urban areas, provide accurate, scaled information about setting and physical structures, these abstract data sources leave out much that is important in understanding an environment. Aerial views not only represent a check on the atlases but can also help establish the relationship of parts of a neighborhood to one another. Figures 13 and 14 suggest the physical isolation of the inward-facing alley houses from the outward-facing street houses. They also suggest the tone of the areas based on the kinds and use of buildings present. ${ }^{24}$

Ground level views are also useful in these regards, as in the case of the photographs of the alley-street intersection: photographs can reveal variations in the isolation of interior alley communities (see Figures 15 and 16). Similarly, views of the interior alley (which are 


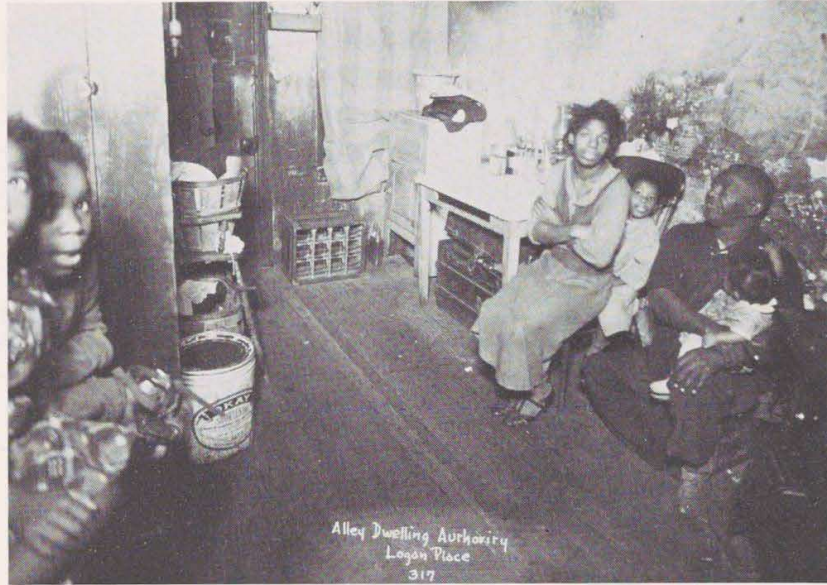

Figure 11 Logan Court NW. No date. Alley Dwelling Authority. (Library, Department of Housing and Community Development, Washington, D.C.)

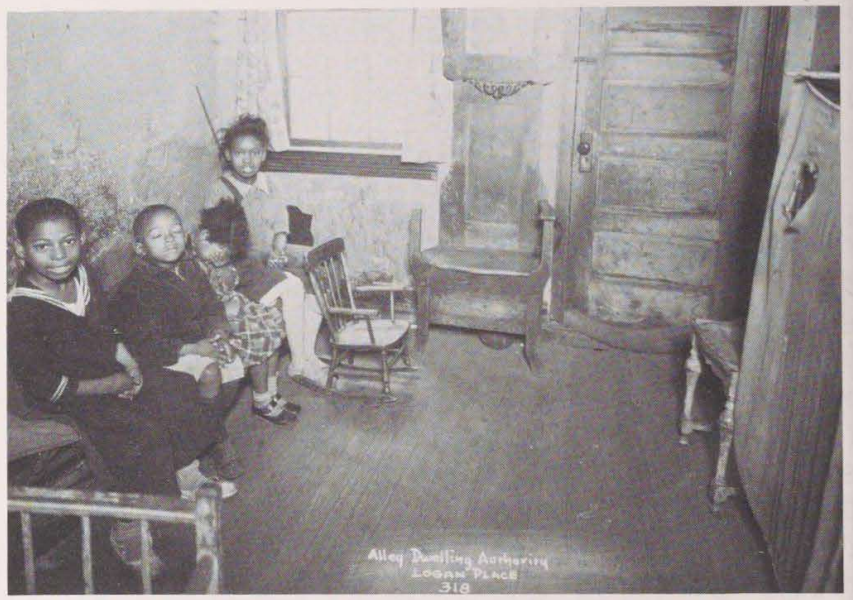

Figure 12 Logan Court NW. No date. Alley Dwelling Authority. (Library, Department of Housing and Community Development, Washington, D.C.)
* No set of sequence photographs of sufficient detail and with supporting narrative evidence was available so that Edward Hall's system for notation of proxemic behavior could be applied (Hall 1963 1003-1026; 1974).
Table 6

\section{Areas of Life Not Covered by Alley Photographs*}

1 Family: relations, activities, boarders, affection, punishment, form, extended kinship networks, separation and divorce.

2 Religion: churches, services, material culture, ministers, congregations, other activities.

3 Rites, rituals, and celebrations: courting, marriage, funerals and wakes, celebrations.

4 Social life: gambling, speakeasies, playing numbers, singing, dancing, musical instruments, lodges and other societies, collective activities.

5 Economic life: work outside the alley, manufacture and sale of alcohol, alley stores, survival strategies collective behavior.

6 "Illegal" behavior: numbers, gambling, prostitution, illegal liquor, violent crime, fighting, violence, juvenile delinquency.

7 Health care: midwifery, folk remedies, pregnancy, childbirth, disease and disability

8 Other: traditional handicrafts, alley resident-nonresident relations, black-white relations, mobility (moving), activities inside dwellings, literacy and reading materials, activities in the alley - early morning, late afternoon, evening, night, teenagers. 


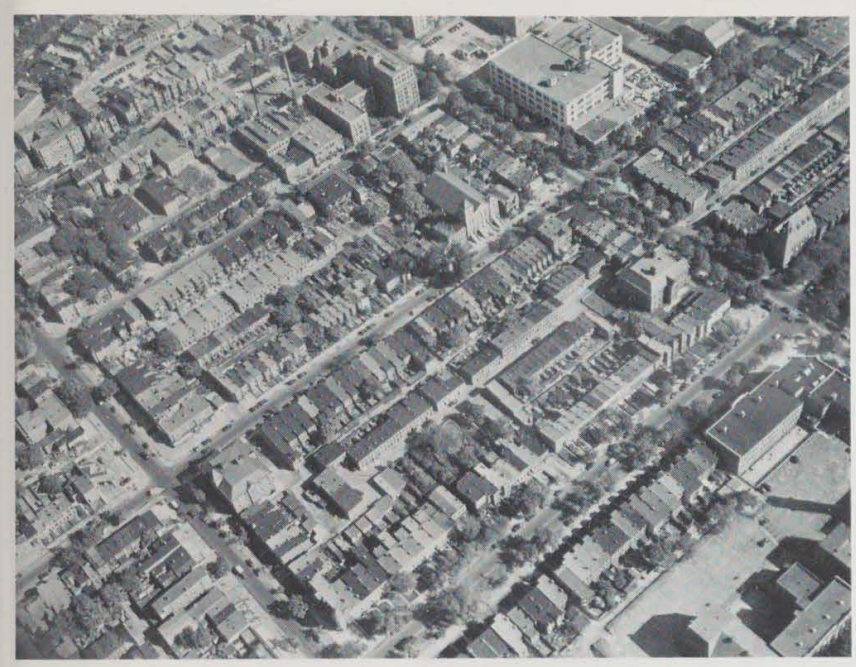

Figure 13 Aerial view:

Logan Court NW. October

6,1939 . Alley Dwelling

Authority. (Library, Depart-

ment of Housing and

Community Development,

Washington, D.C.)
Figure 14 Across the street from the imposing Senate Office Building, hidden behind the fronts of good housing, are the unsanitary and dilapidated dwellings comprising Schotts Alley. They are plainly visible in this aerial photograph on the interior of the square. December 1, 1941. Alley Dwelling Authority. (Library, Department of Housing and Community Development, Washington, D.C.)

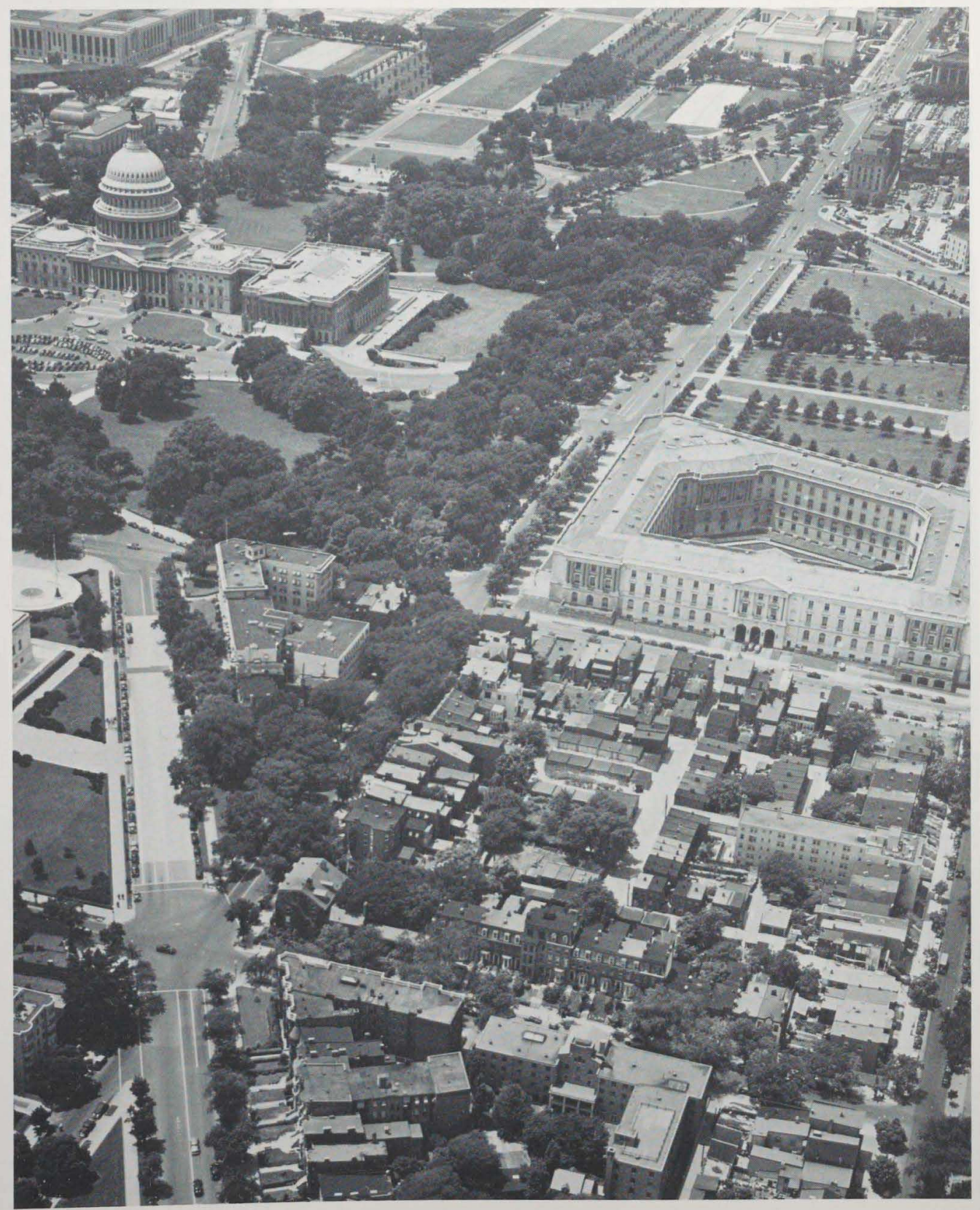




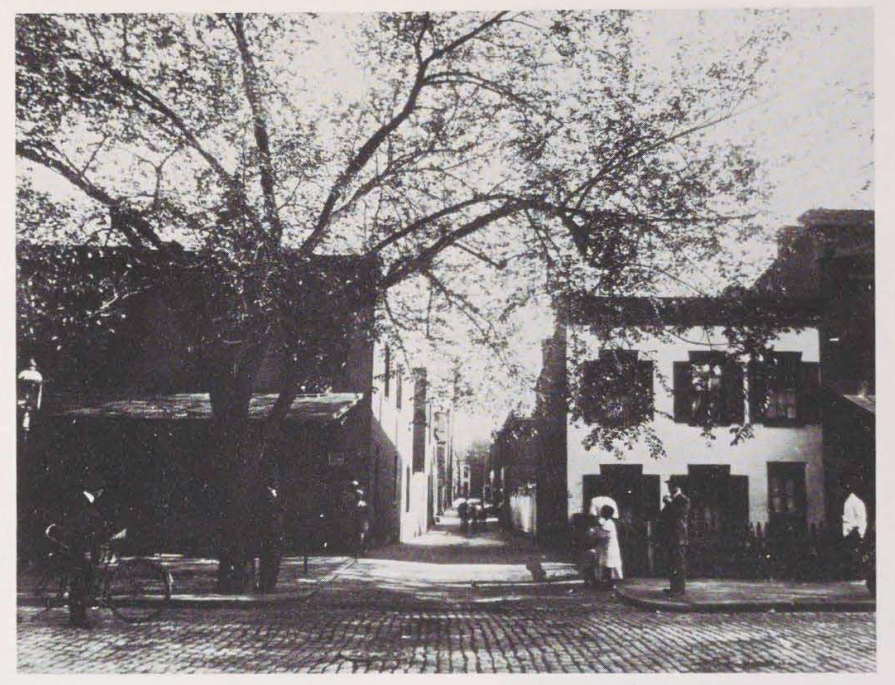

Figure 15 Willow Tree Alley SW. 1912-1913? Roy E. Haynes. (Roy E. Haynes to John Ihlder. John Ihlder Papers, Franklin D. Roosevelt Presidential Library, Hyde Park, N.Y.)

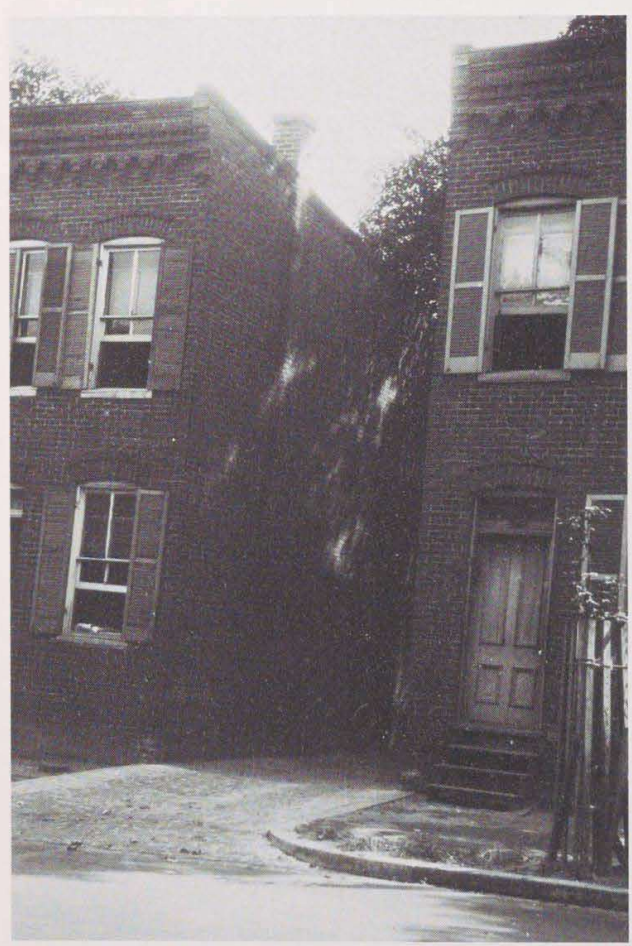

Figure 16 Bell's Court NW. No date. John Ihlder. (John Ihlder Papers, Franklin D. Roosevelt Presidential Library, Hyde Park, N.Y.)

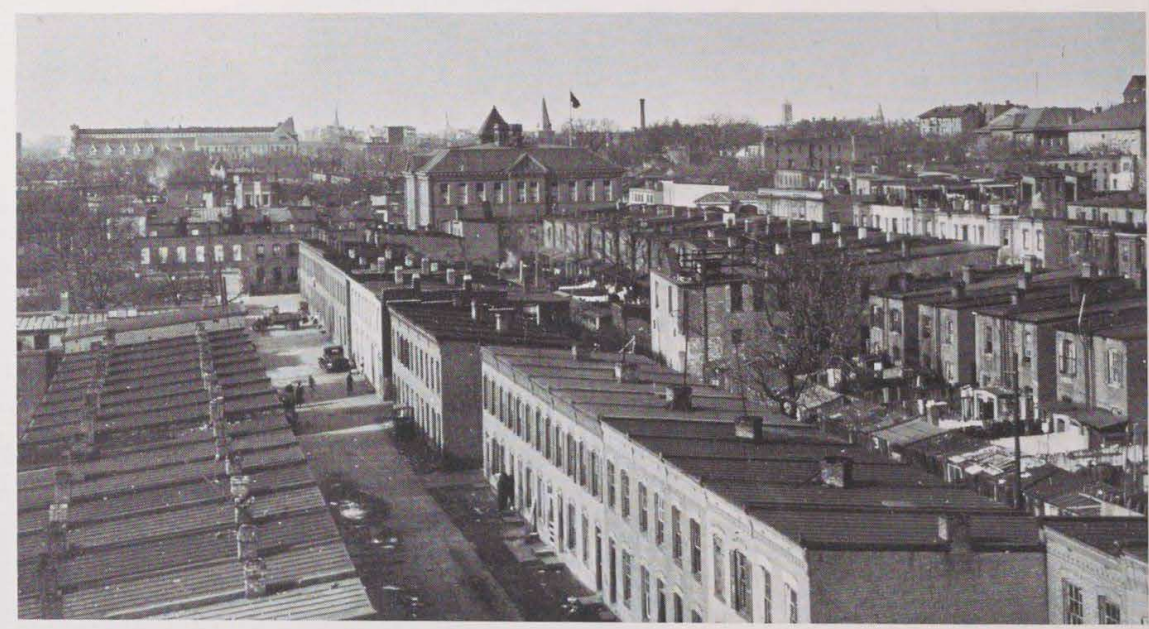

Figure 17 Alley dwellings between Pierce Street, L Street, First Street, and North Capitol Street, NW. November 1935. Carl Mydans. (Farm Security Administration Collection, Library of Congress)

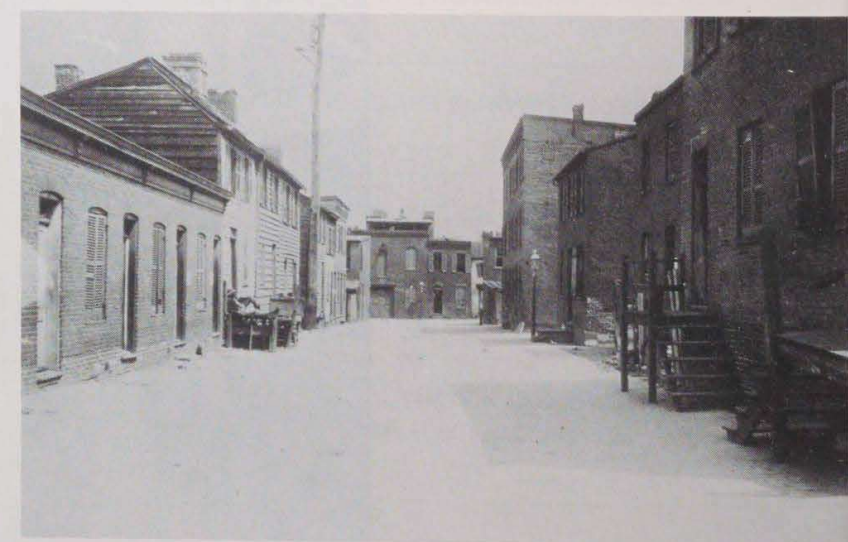

Figure 18 Willow Tree Alley SW. 1912-1913? Roy E. Haynes. (Roy E. Haynes to John Ihlder. John Ihlder Papers, Franklin D. Roosevelt Presidential Library, Hyde Park, N.Y.) 


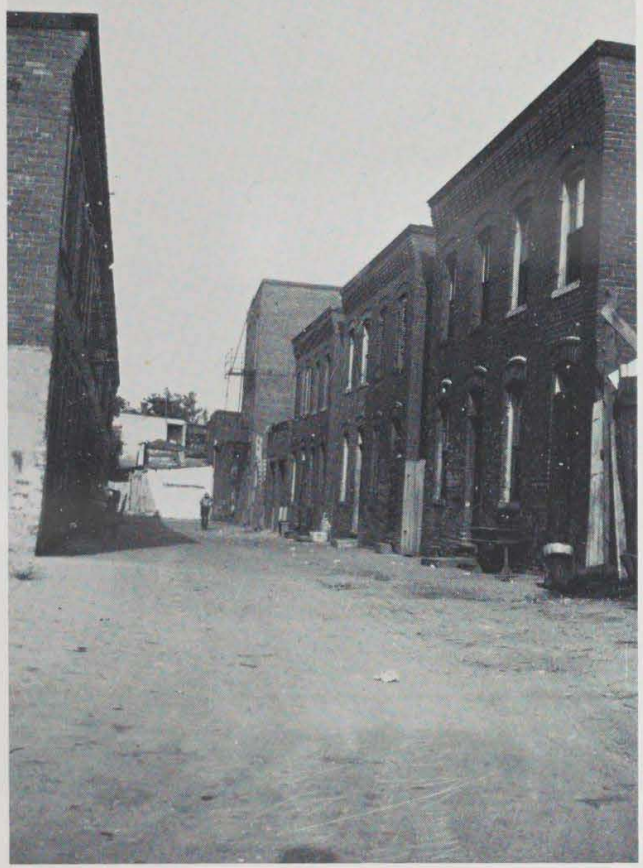

Figure 19 Alley dwellings,

1928. John Ihlder.

(John Ihlder Papers,

Franklin D. Roosevelt

Presidential Library, Hyde

Park, N.Y.)

Figure 20 Negro tenement houses on Fenton Place in the Northeast section near the Capitol Building. September 1941. Marion Post Wolcott. (Farm Security Administration Collection, Library of Congress)

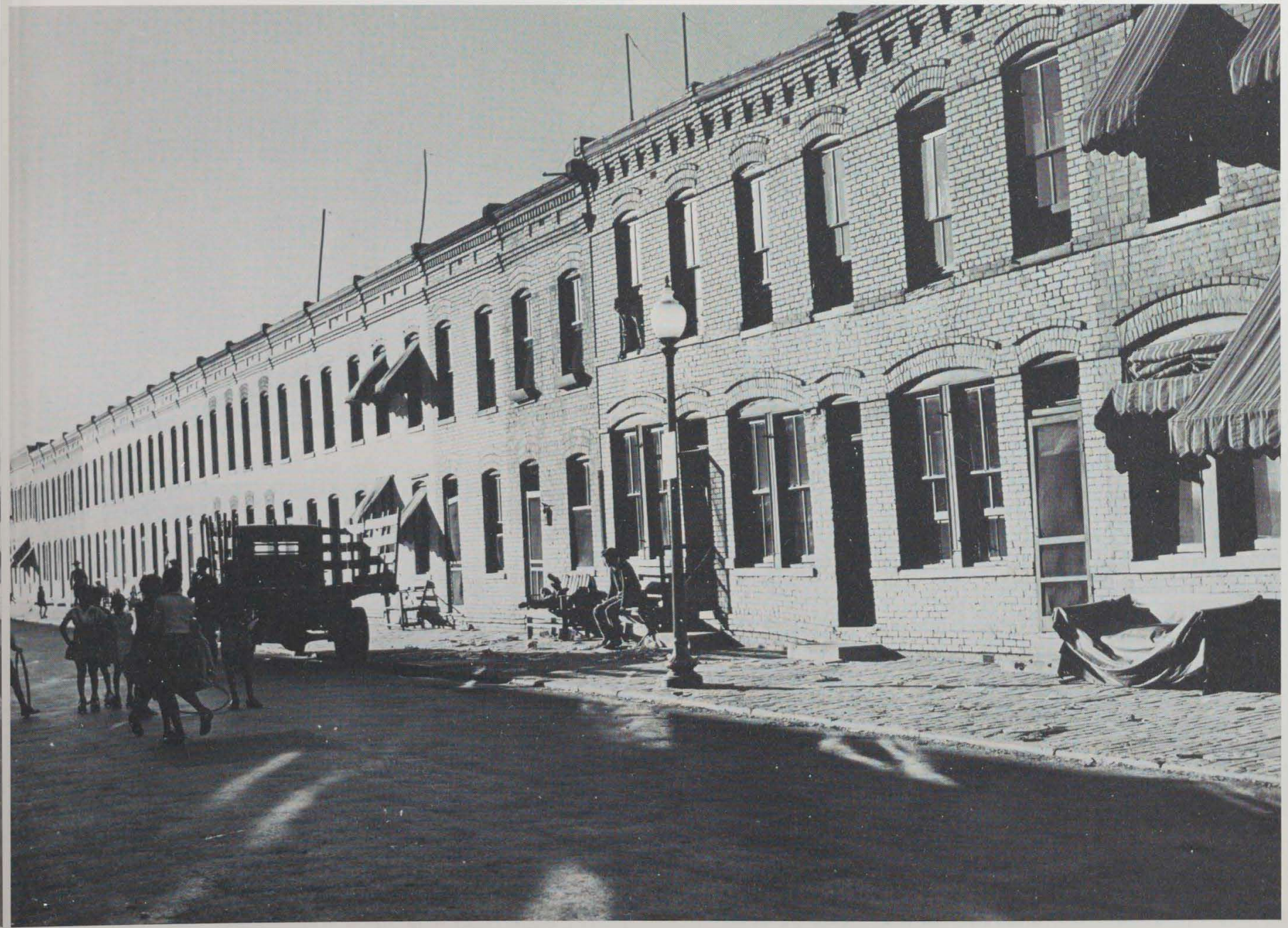


the most numerous in the compilation), more than any other source, make it possible to establish the environmental context of alley life; the extent of isolation from the surrounding streets and houses is clear in Figures 17,18 , and 19 as well as in many others. While these views alone do not establish the separate, independent development of alley communities, they certainly do establish the presence of a physical environment that could encourage this development. Finally, photographs make it possible to compare similar physical environments and their uses; see the minor street in Figure 20.

Save for the limited information available in building and repair permits and that which can be learned by studying the few persisting alley houses in the city, photographs provide the only source to determine construction methods (determined from demolition photographs like Figure 22), exterior building conditions over the years, and the extent of maintenance. It is also possible, with information from other sources, to develop a chronological typology of house type (see Figure 21) and to trace in the later years their transformation into warehouses and garages or their metamorphosis into expensive residences of white-collar workers (see Figure 24).

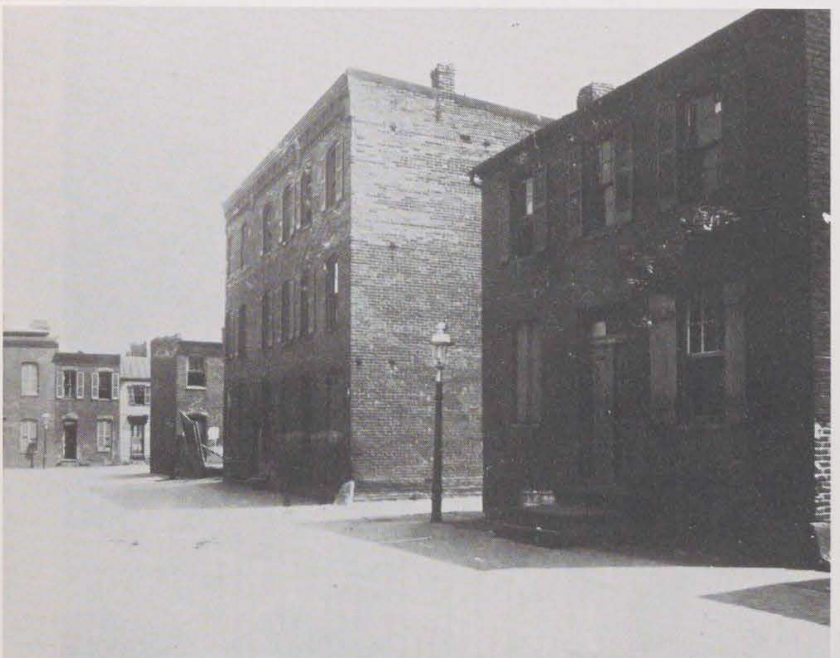

Figure 21 Willow Tree Alley SW. 1912-1913? Roy E. Haynes. (Roy E. Haynes to John Ihlder. John Ihlder Papers, Franklin D. Roosevelt Presidential Library, Hyde Park, N.Y.)

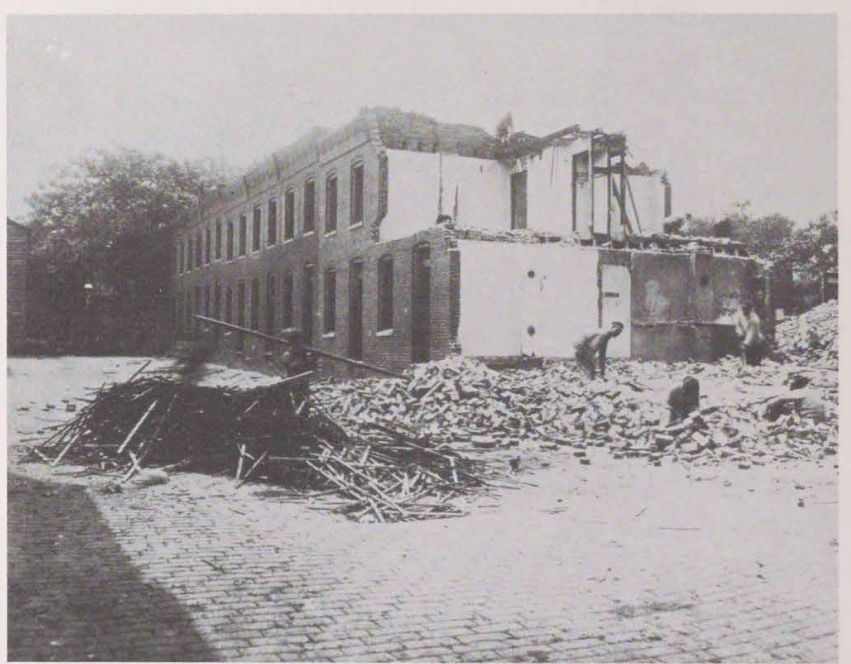

Figure 22 Willow Tree Alley SW. 1912-1913?

Roy E. Haynes. (Roy E.

Haynes to John Ihlder. John Ihlder Papers, Franklin D. Roosevelt Presidential Library, Hyde Park, N.Y.)
Figure 24 Marks Court SE, "restored." July 1972 James Borchert. (Columbia Historical Society)

Figure 25 Backyard and privy near the Government Printing Office. The pump on the right supplies water for the house behind the privy. September 1935. Carl Mydans. (Farm Security Administration Collection, Library of Congress) 


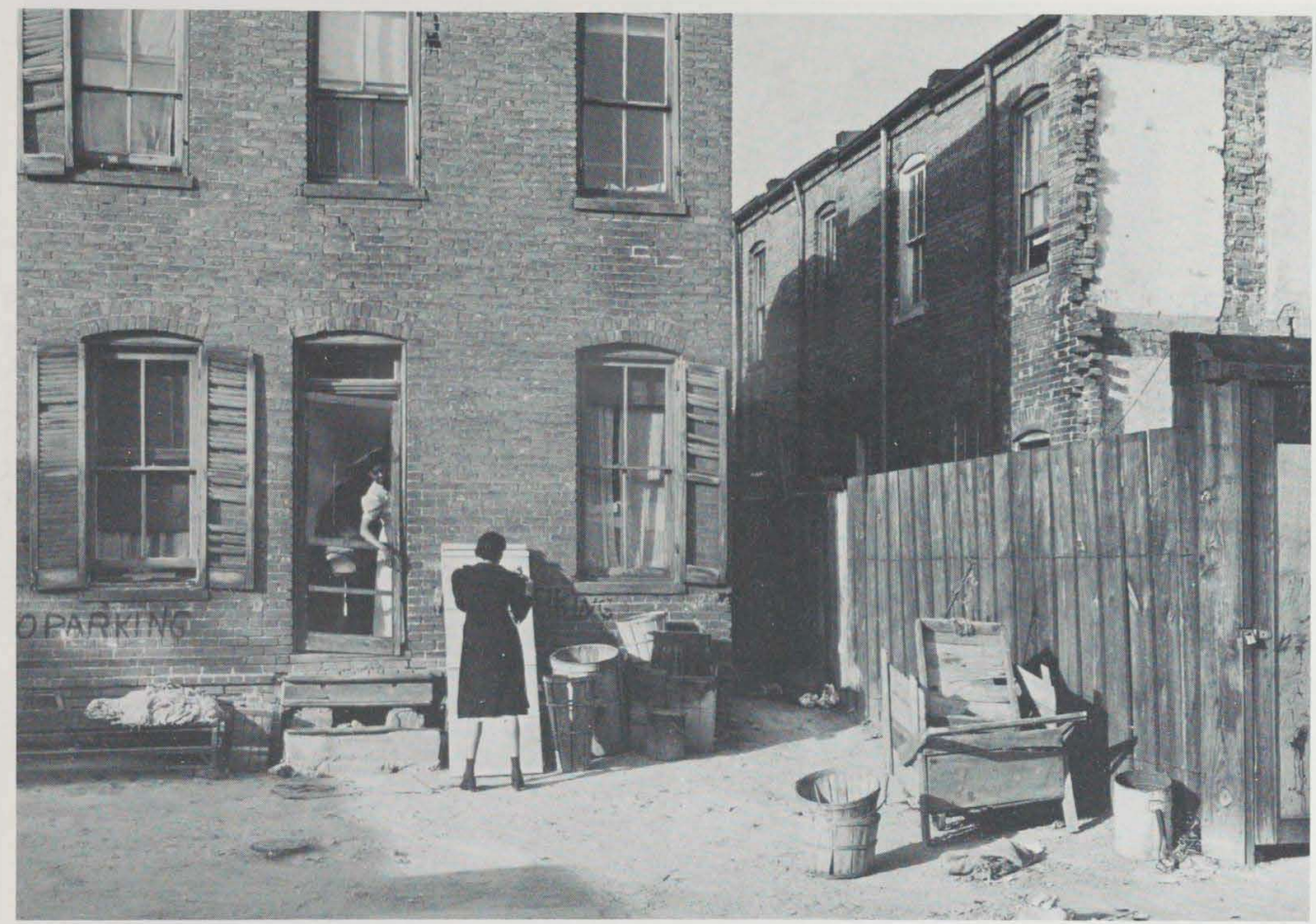

Figure 23 Alexandria

Court between $\mathrm{K}$ and $\mathrm{L}$ streets NW. A woman and her two children have lived in four small rooms eight and one-half years and pay $\$ 12.50$ a month for rent. Water and a privy are in the yard. Rents have gone up for nearby homes but not hers. September 1941. Marion Post Wolcott. (Farm Security Administration Collection, Library of Congress)
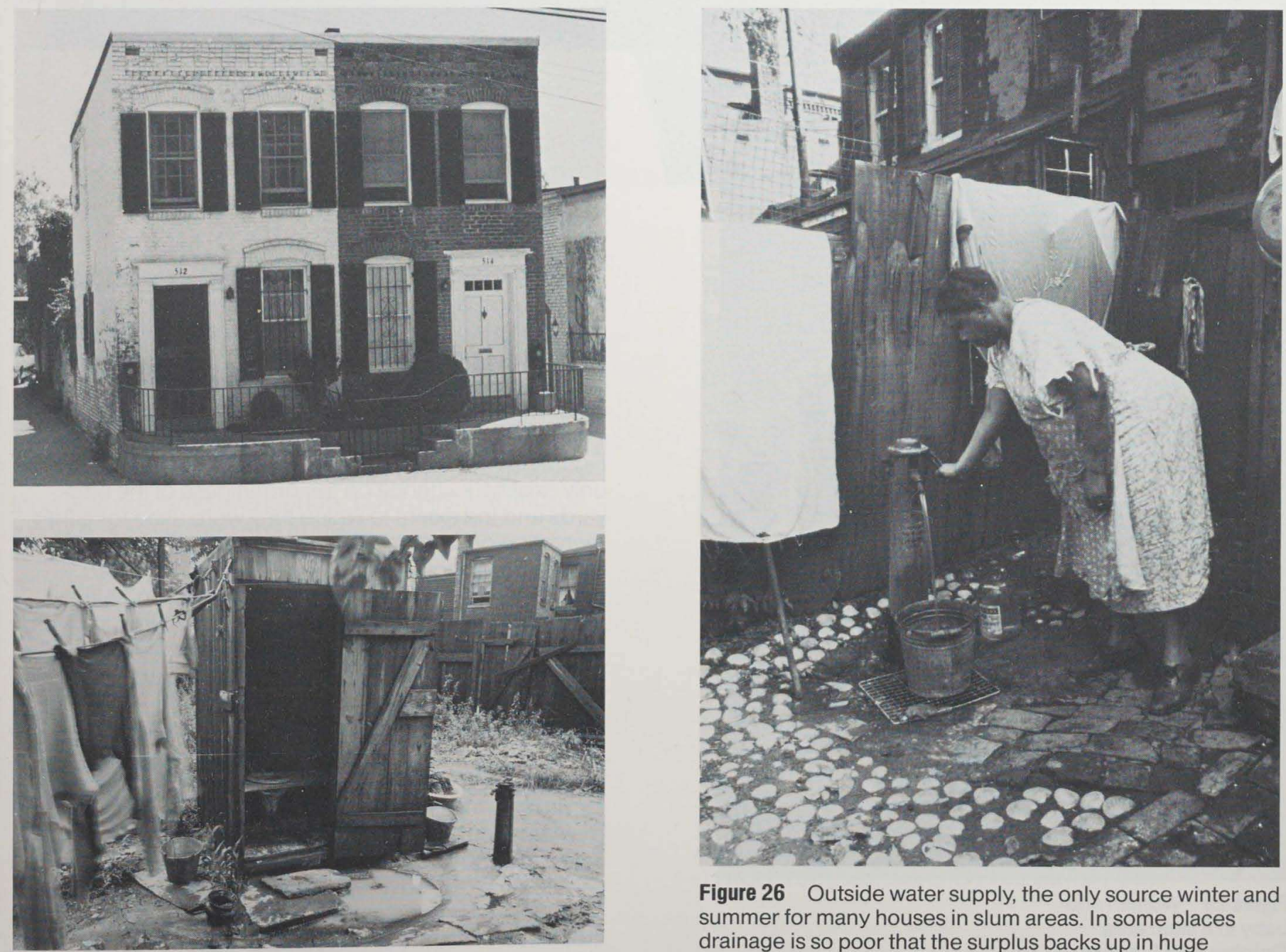

Figure 26 Outside water supply, the only source winter and summer for many houses in slum areas. In some places drainage is so poor that the surplus backs up in huge puddles. July 1935. Carl Mydans. (Farm Security Administration Collection, Library of Congress) 
Figure 27 Down in the slums. This was a combination bedroom-dining roomkitchen in one of the old houses demolished by the National Capitol Housing Authority on the site of the Carrollsburg Dwellings. Note the oil lamps and the stove. No date. Alley Dwelling Authority. (Library, Department of Housing and Community Development, Washington, D.C.)

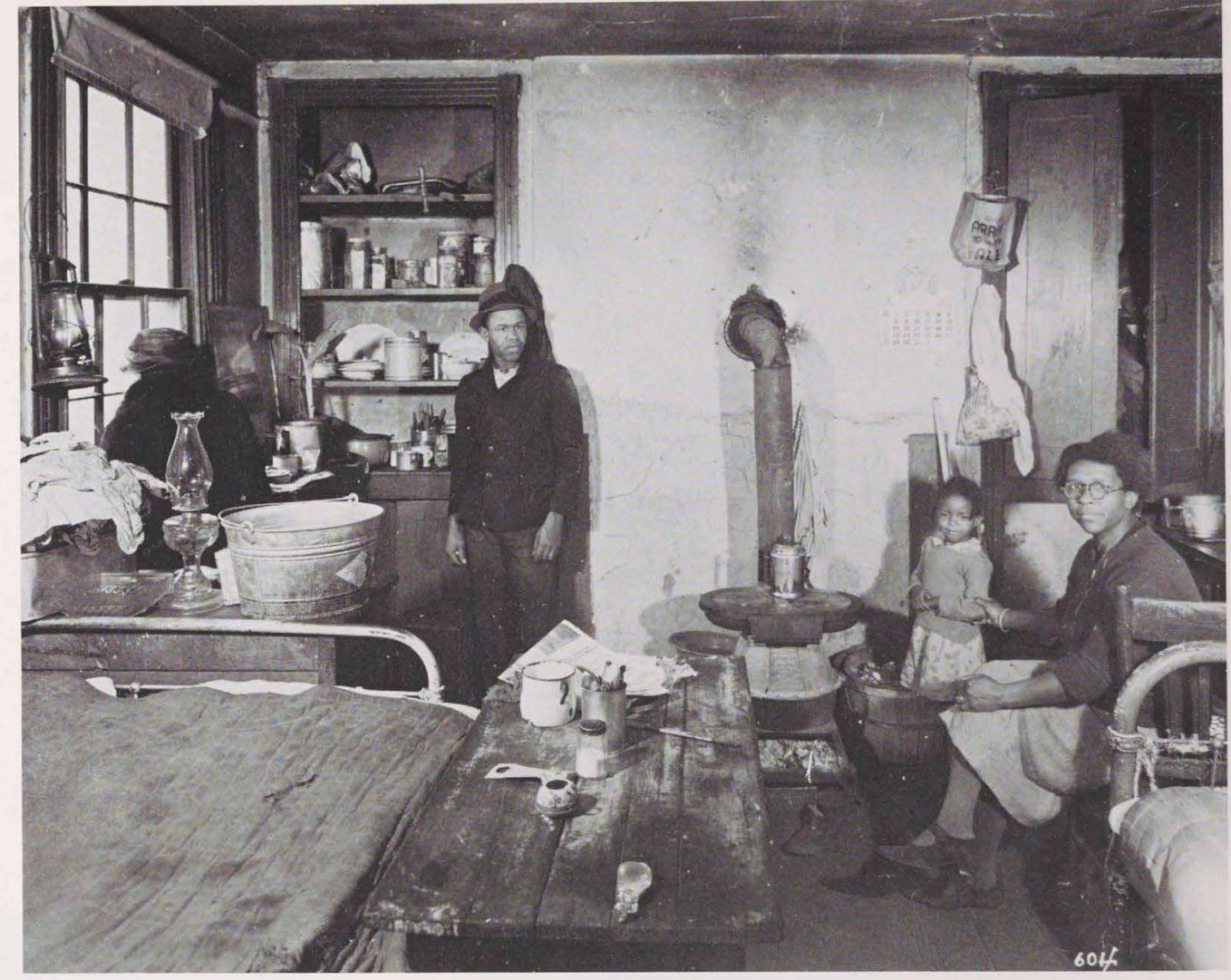

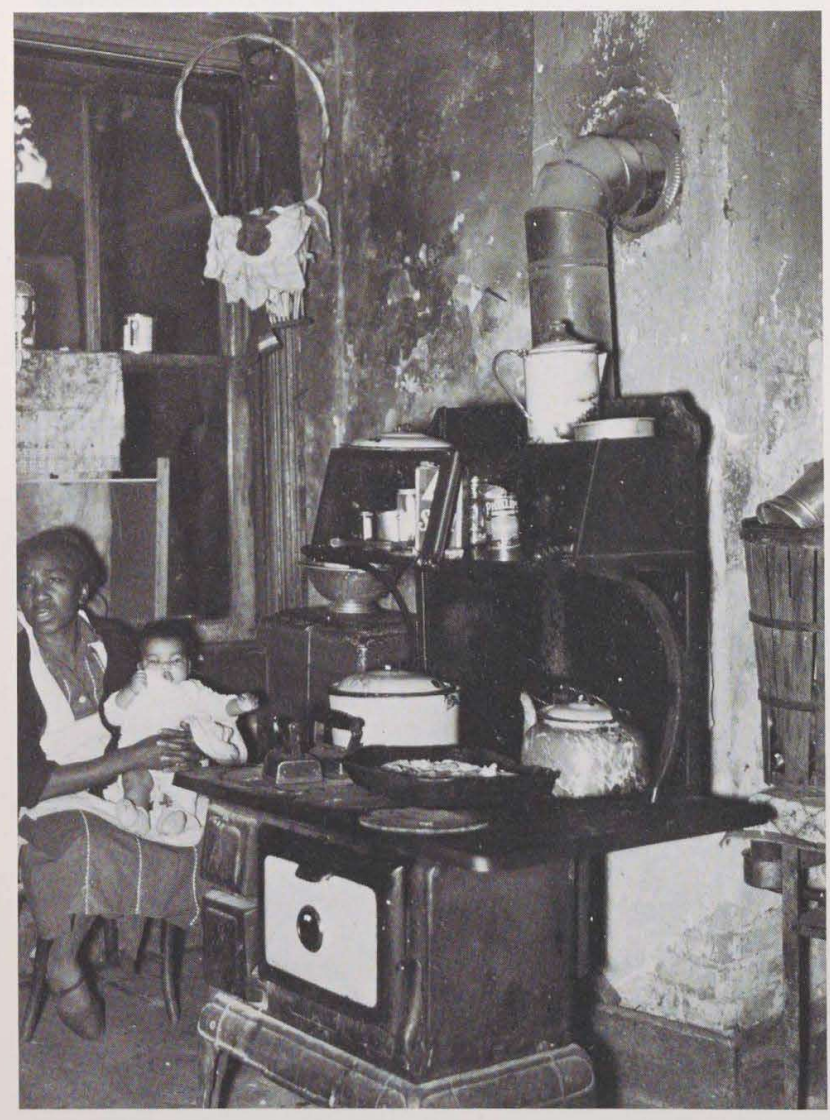

Figure 28 Woman and baby in a slum area.

October 1937. Arthur

Rothstein. (Farm Security Administration Collection, Library of Congress)
Although limited in number, photographs represent the best and largest source of information on the more private areas of the backyard and house interior, although some participant-observer accounts do provide supportive evidence. A substantial number of photographs document the presence and condition of two backyard institutions: the water hydrant and the outhouse (see Figures 25 and 26). Photographs also represent the only existing evidence on the orderliness of the backyards and the extent to which they were used for either recreation or storage. The latter was especially important because the backyard was the site of storage for scavenged items collected (often by children) in the surrounding area. The presence of such items in photographs helps support the descriptive information on alley life that suggests this was a common activity to provide funds in times of need.

Unfortunately there are few interior photographs, and many of these were taken after residents vacated prior to demolition. Nevertheless, photographs are valuable for uncovering interior conditions (both decoration and maintenance) of the building itself as well as the use of interior space and decoration made by residents themselves. While alley dwellers faced considerable overcrowding and persistent landlord refusal to make repairs, they nevertheless found ingenious ways to respond to these conditions despite limited resources (see Figures 
Figure 29 O'Brien's Court NW. September 14, 1935. Alley Dwelling Authority. (Library, Department of Housing and Community Development, Washington, D.C.)

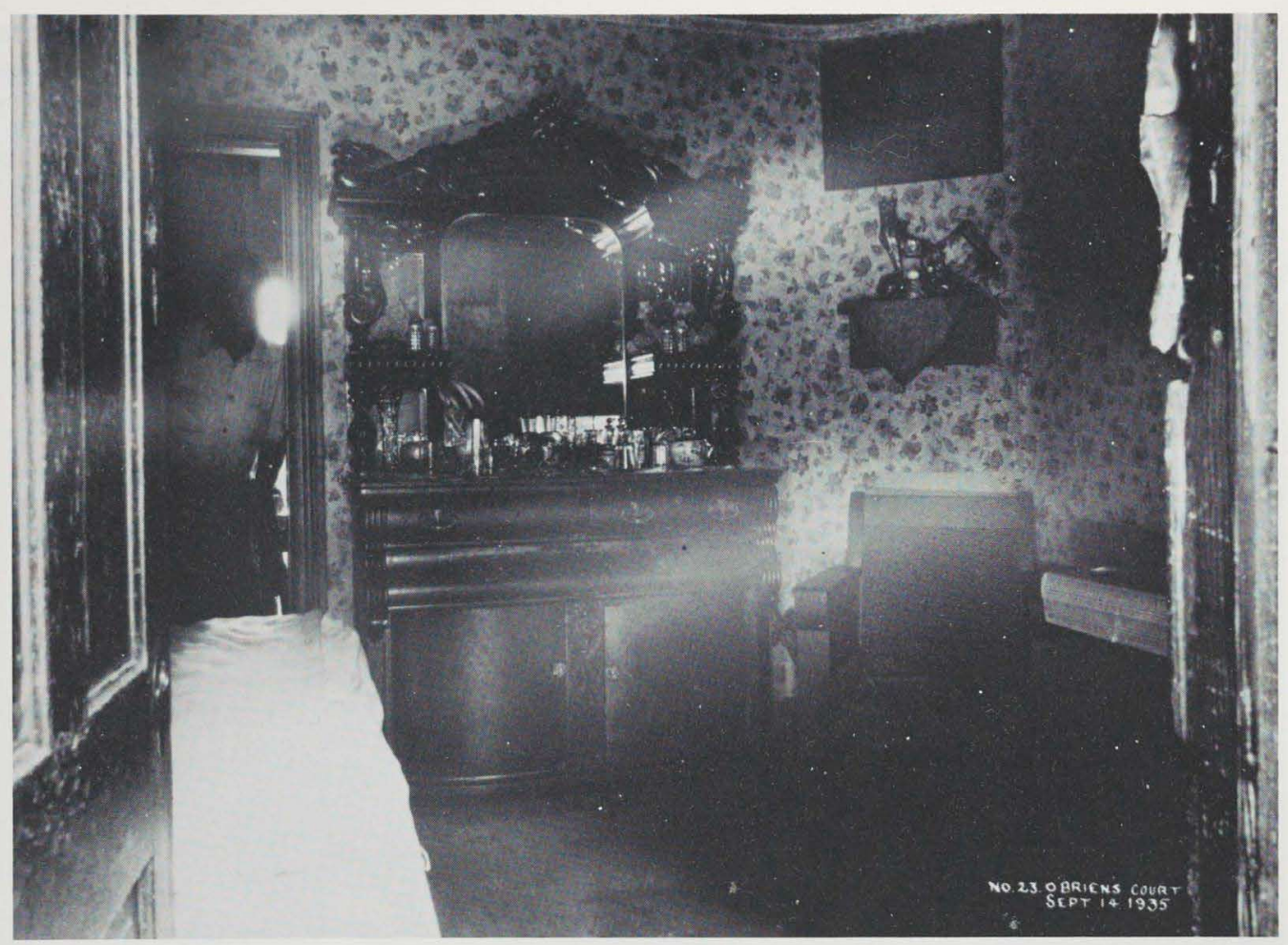

$11,12,27,28,29)$. Although photographic evidence is far from conclusive on this issue, it does provide valuable insight that supports descriptive findings from social surveys and participant-observer studies of alley life. Finally, photographs help establish the extent of orderliness and cleanliness that residents sought to maintain, as well as to suggest activities and focal points within the house (i.e., the kitchen as the center of family life where food was prepared and laundry, both personal and for income, was washed and ironed).

\section{Behavioral Landscape}

One of the critical issues of the larger study concerned the extent to which the urban environment adversely affected folk migrants, restricting their ability to maintain order and control. If alley dwellers were able to use and remake their environment to fit their own needs, then the impact of urbanization was considerably less than many previous studies had concluded.

Photographs here represent an almost uniquely unobtrusive means to evaluate the behavioral landscape. While descriptive accounts can be helpful in providing supportive evidence, photographs are virtually alone in their ability to record unintentionally (as well as intentionally) information on how people use and adapt their environment to their own needs, or fail to do so. Moreover, it is clear that this issue largely if not entirely escaped the concern of alley photographers and observers of alley life except to the extent that they found this behavior pathological; Weller warned that "alley houses lacked privacy, lack provisions for making family life distinct and sacred. Instead there is a discord, disorder and a constant seething 'mixup' of the population' (Weller 1909:69; Borchert 1980:246-266). 


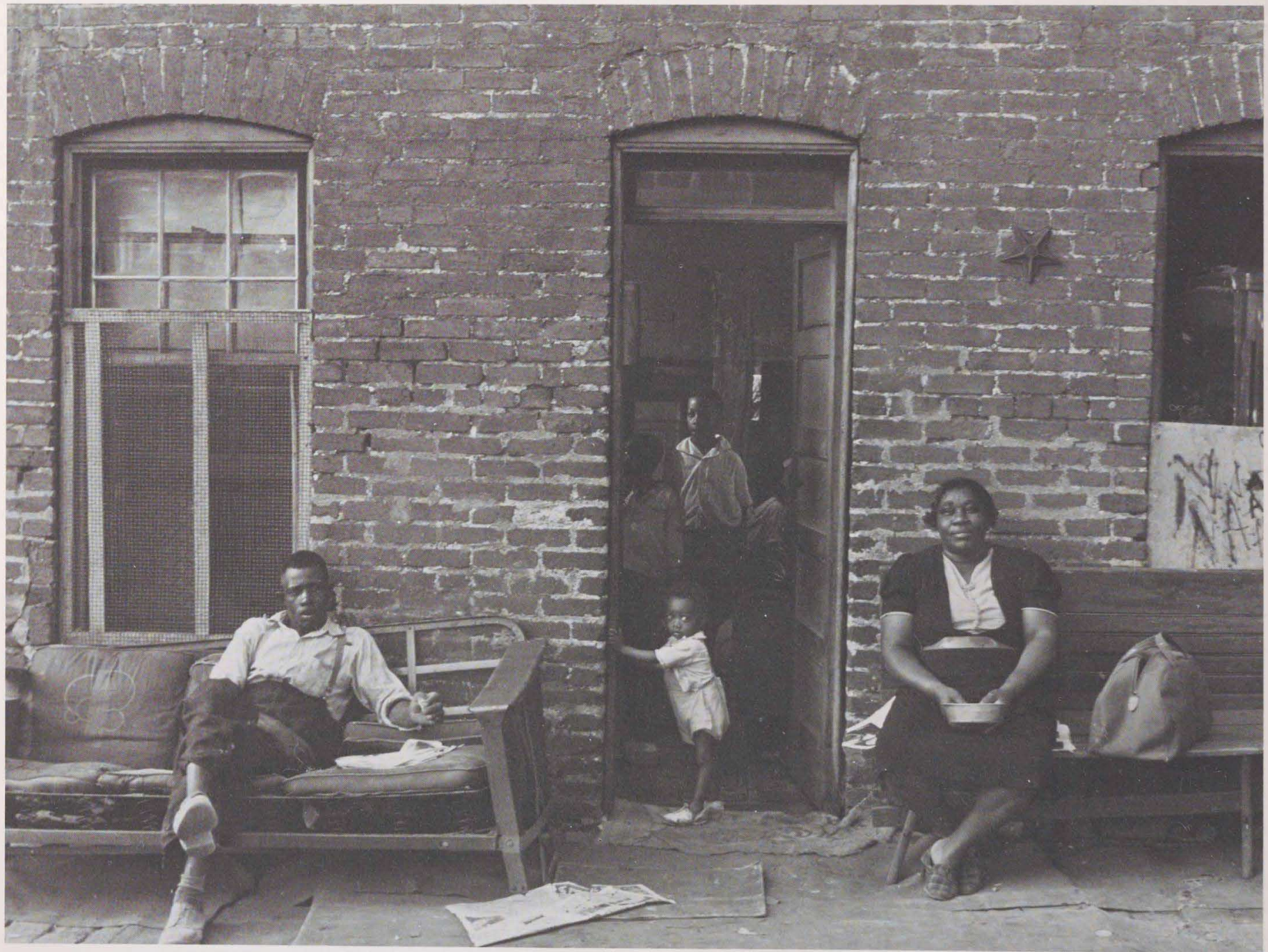

Figure 30 Family and

their home in an alley

dwelling. July 1941. Ed

Rosskam. (Farm Security

Administration Collection,

Library of Congress) 
What Weller and other observers misinterpreted was the presence of extended kinship networks within the alley that provided the first level of organization; a second, more amorphous level of activity involved the alley neighborhood in an informal organization that provided social services, recreation, social control, and turf maintenance. Both extended kinship network and informal alley community required high levels of faceto-face contact. To facilitate this, alley dwellers literally remade their environments. One key aspect of this transformation had to do with the use of the alley itself: residents converted the alley into a multipurpose commons and community center (for example, see Figure 3 of Logan Alley in 1908 and Figure 33 of the same alley in 1935, or Figure 2 of Schotts Court in 1941 and Figure 34 taken at almost the same point in the same alley in 1949). They also turned their homes inside out by projecting part of the house into the alley and opening the rest to the alley. Photographs provide ample evidence of household furniture (for example, see Figures 19 , 30,31 , and 32) in the alley itself along with other kinds of furniture and articles that could be used for sitting and lounging. The use of these articles as well as the general use of the alley for neighboring was extensive throughout the daytime hours that photographers recorded alley landscapes (see Figures 1, 2, 3, 4, 8, 15, 17, 18, 30, 31 $32,33,34,35,36,37,38,39,40,41,43$, and 45 ). Partial descriptive evidence from other sources suggests that this activity intensified when men, women, and children returned from work or school in the late afternoon and early evening, and this neighboring persisted well into the night. (Some photographs suggest that this activity also continued into the winter months; see Figure 45.) Moreover, while builders had installed small doors and windows in the facades, alley dwellers figuratively "knocked out" these tentative openings. It was not unusual to find heads sticking out of doors and windows into the alley, or heads pushed into first-story doors and windows (see Figures 3, 8, 33, 34, 35, and 37). Neighbors apparently moved back and forth from house to alley to neighbor's house, unimpeded by either physical or social barriers. In addition, the open alley house served as a symbol of the interdependence of the residents and made visual surveillance, social control, and maintenance of defensible space much easier (Borchert $1980: 102-117)$. While this analysis was verified by fragmentary descriptive evidence, a comparison of the use of space and house facade of blue-collar alleys with that of white-collar alleys of the 1970 s made clear the significance of each environment for its residents (Borchert 1979). ${ }^{25}$

A note of caution should be added to this assessment. Since the researcher analyzing historical photographs cannot test conclusions by interviewing residents or constructing a sociogram of alley interactions, findings on the extent of interaction must be tentative. Other sources can strengthen these conclusions; in this case descriptive studies and theoretical information provide support for these findings.

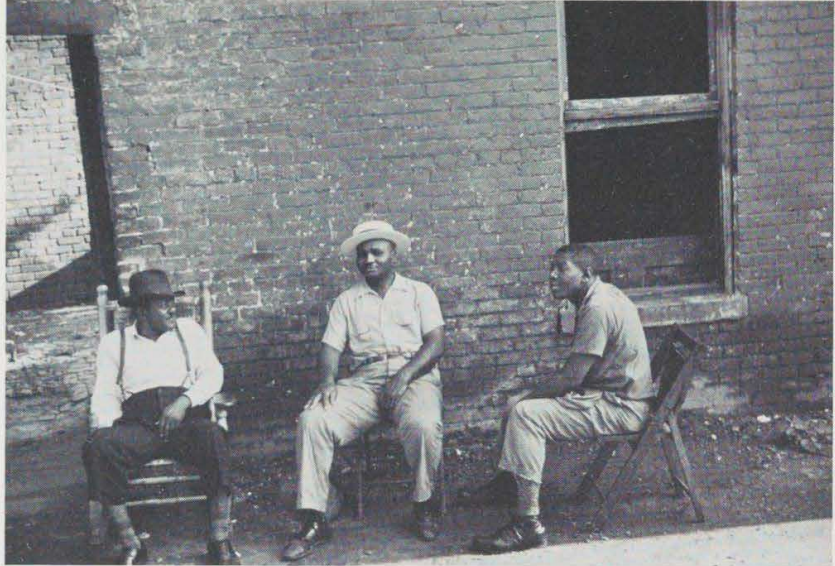

Figure 31 Negroes in front of their alley homes in the alley dwelling area. July 1941. Ed Rosskam. (Farm Security Administration Collection, Library of Congress)

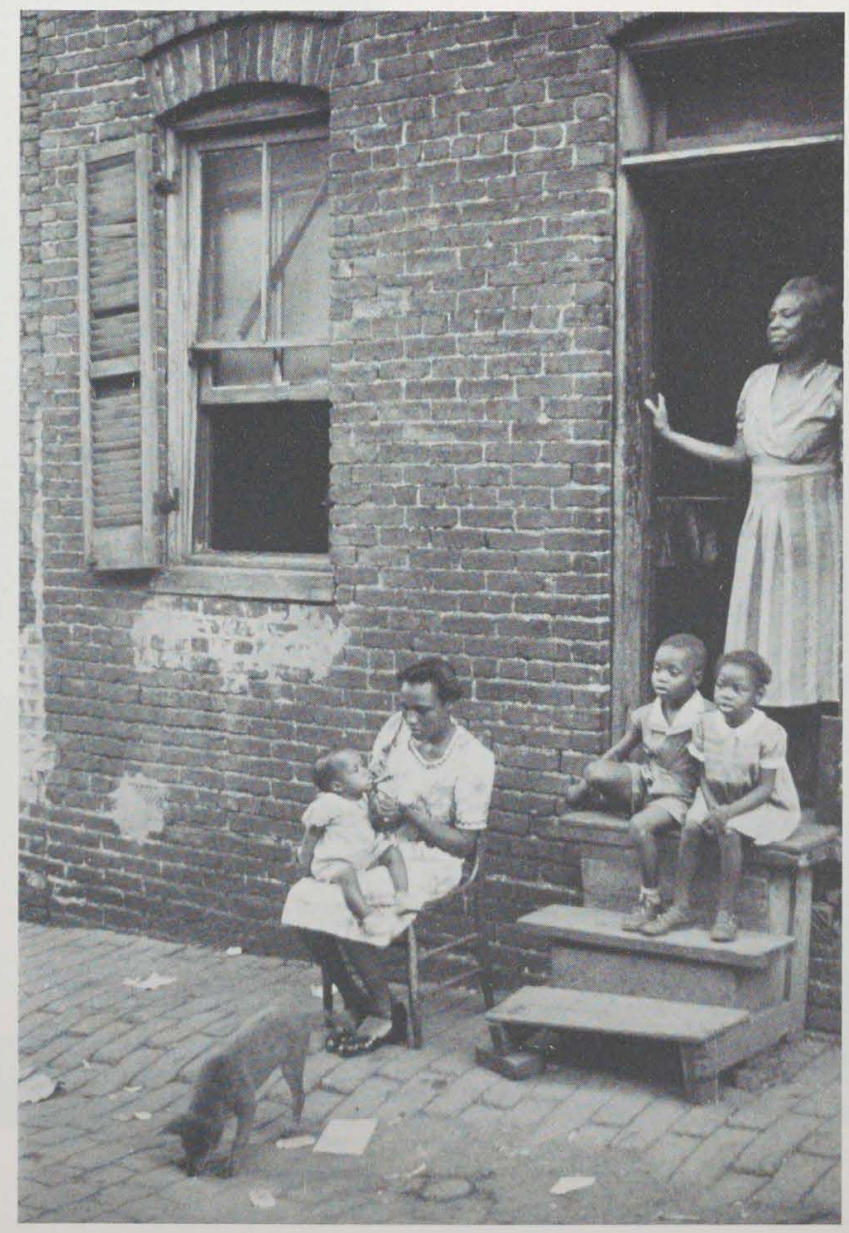

Figure 32 Family in front of their alley dwelling. The older woman is a charwoman in a U.S. Government office building. July 1941. Ed Rosskam. (Farm Security Administration Collection, Library of Congress) 


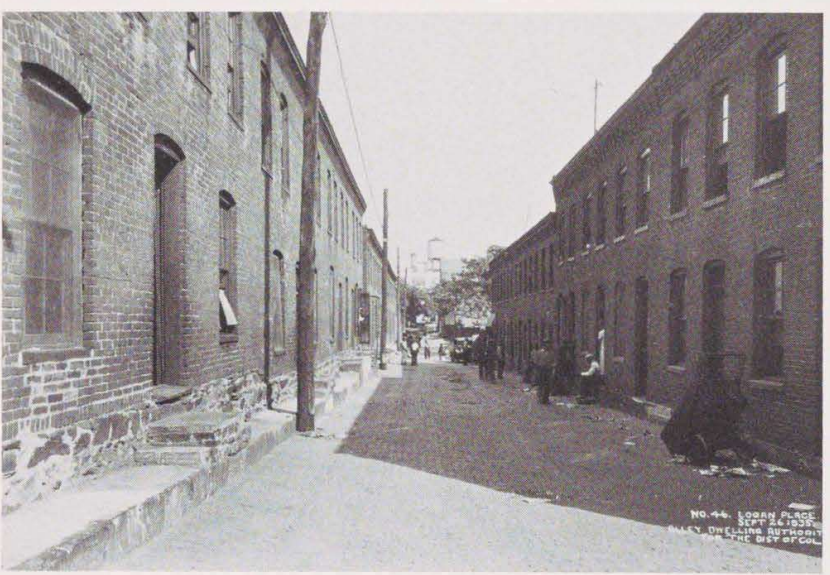

Figure 33 Logan Court NW September 26, 1935. Alley Dwelling Authority. (Library, Department of Housing and Community Development, Washington, D.C.)

Figure 34 Schotts Alley NE, showing row of houses in foreground. March 29, 1949. Alley Dwelling Authority-



National Capitol Housing Authority. (Library, Department of Housing and Community Development, Washington, D.C.)

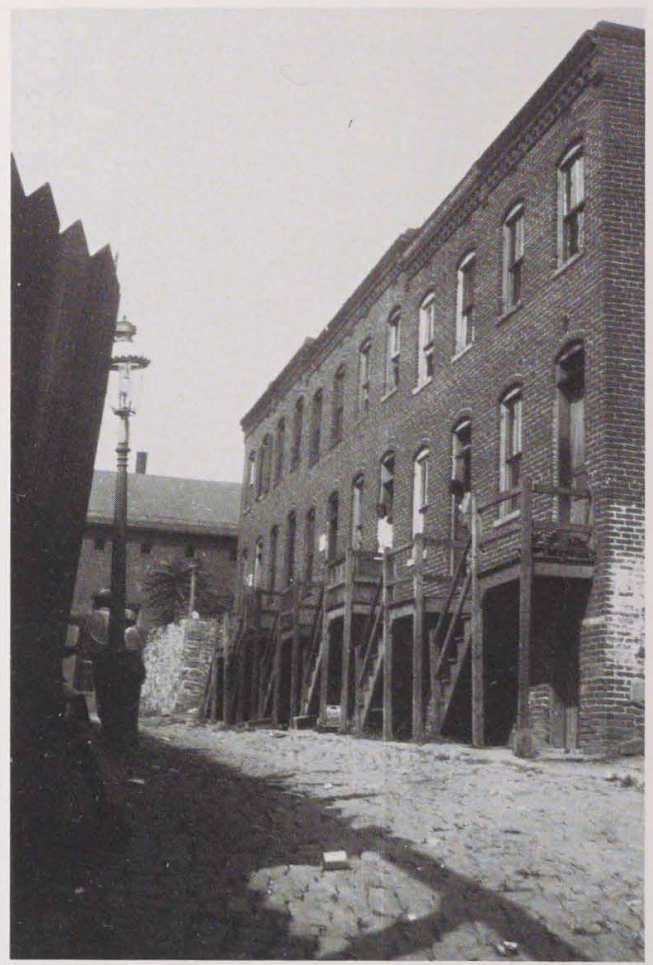

AFigure 35 Bell's Court NW. No date. John Ihlder. (John Ihlder Papers, Franklin D. Roosevelt Presidential Library, Hyde Park, N.Y.) 


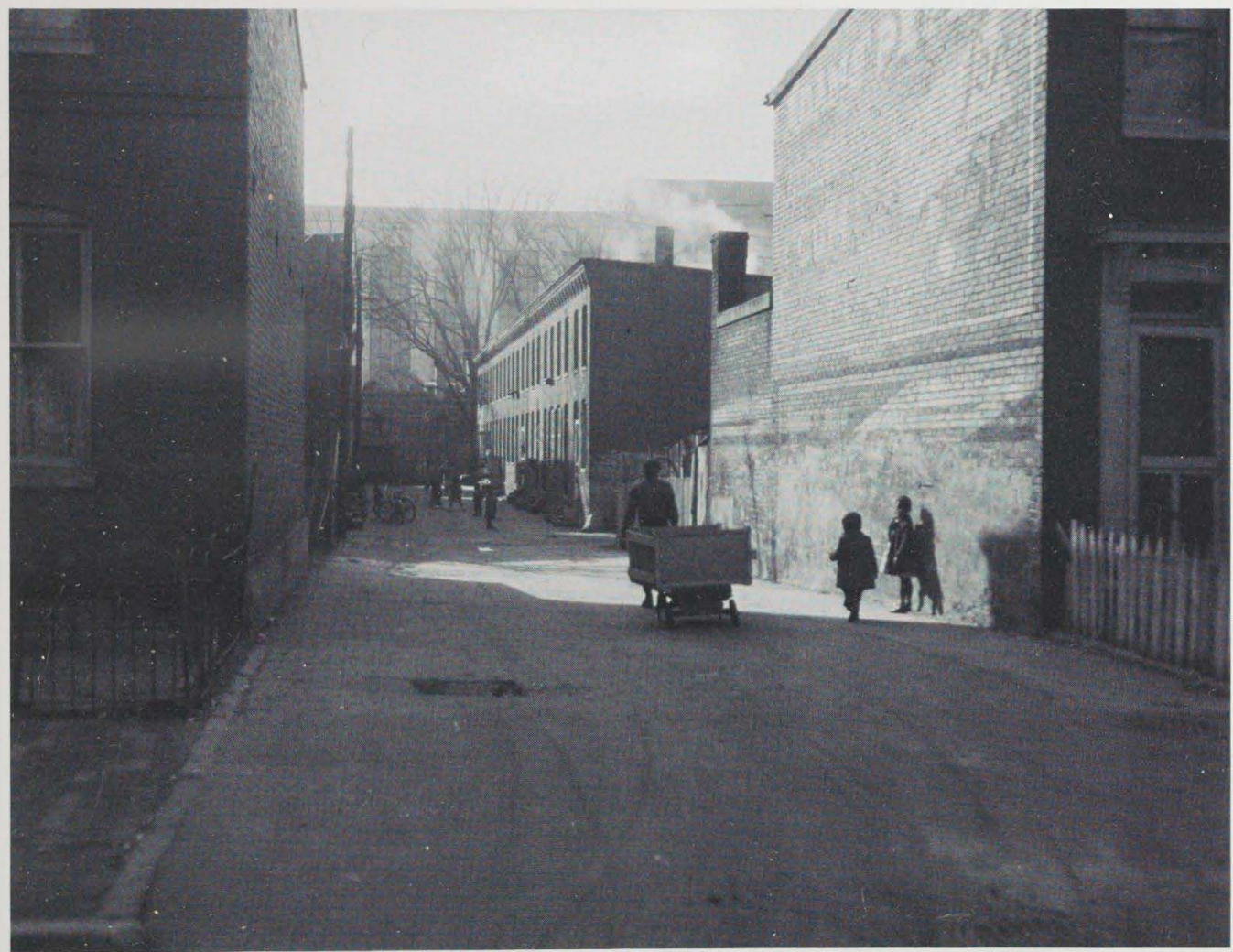

Figure 36 Slums and Social Security Building from $B$ and $1 / 2$ Street SW (Wonder's Court SW). March 1951. National Capitol Housing Authority. (Library, Department of Housing and Community Development, Washington, D.C.)

\section{Childhood}

Photographs also provide some insights into the childrearing process and the material culture of alley children - information notably absent from most other sources. "Portraits" suggest the type and quality of clothing, while less formal photographs indicate the nature of informal play, material culture of play, child labor, child care, and family setting (see Figures 2, 4, 5, 6, 7, 9, 11, 12, 23, 27 , $28,30,32,36,38,39,40$, and 43).

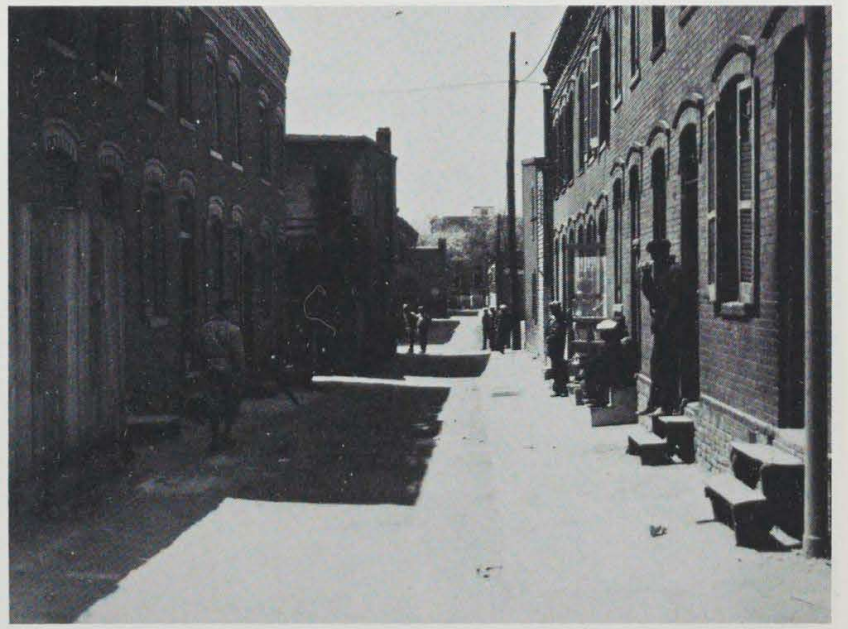

Figure 37 No caption. No date. Office of the Files of the Director John F. Nolen, Jr. (1933-1958). (Records of the National Capitol Planning Commission, National Archives, Record Group 328) 


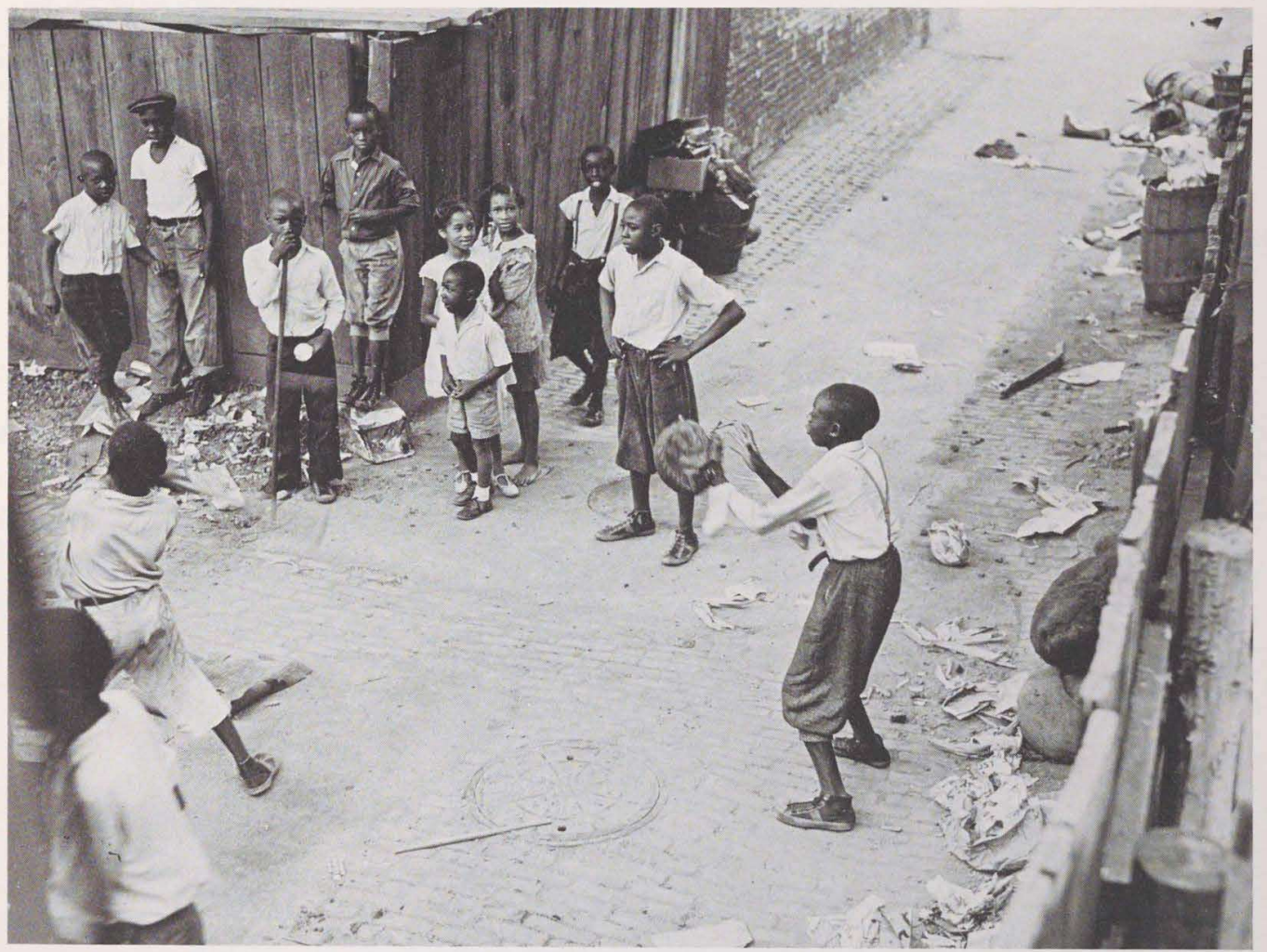

Figure 38 Interior No. 3. Baseball game in alley at rear of old London Court houses (group of five). Note the rubbish. No date. Alley Dwelling Authority. (Library, Department of Housing and Community Development, Washington, D.C.)

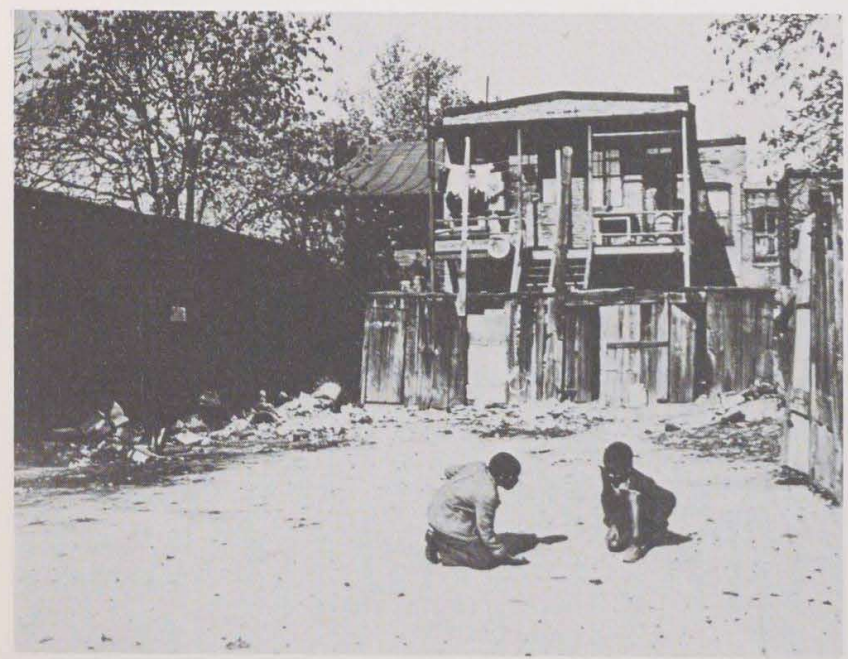

Figure 39 Two Negro

boys shooting marbles in

front of their homes.

November 1942. Gordon

Parks. (Farm Security

Administration Collection,

Library of Congress)

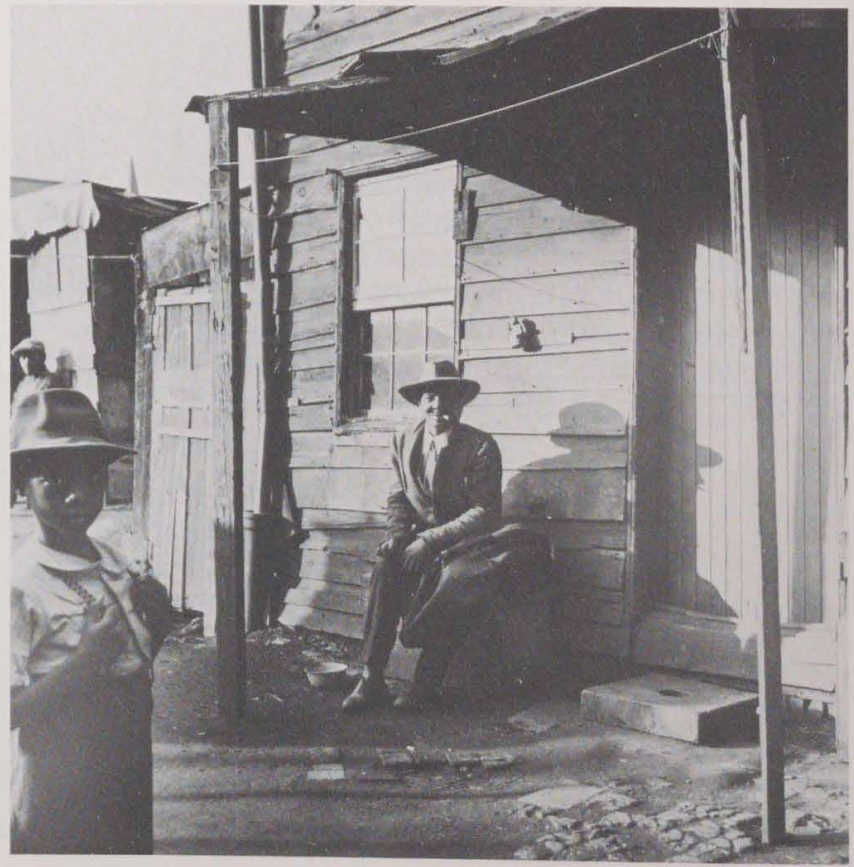

Figure 40 Negroes in front of their alley dwelling near the Capitol. July 1943. Esther Bubley. (Farm Security Administration Collection, Library of Congress) 




Figure 41 Traveling evangelist and his equipment. July 1941. Ed Rosskam. (Farm Security Administration Collection, Library of Congress) 


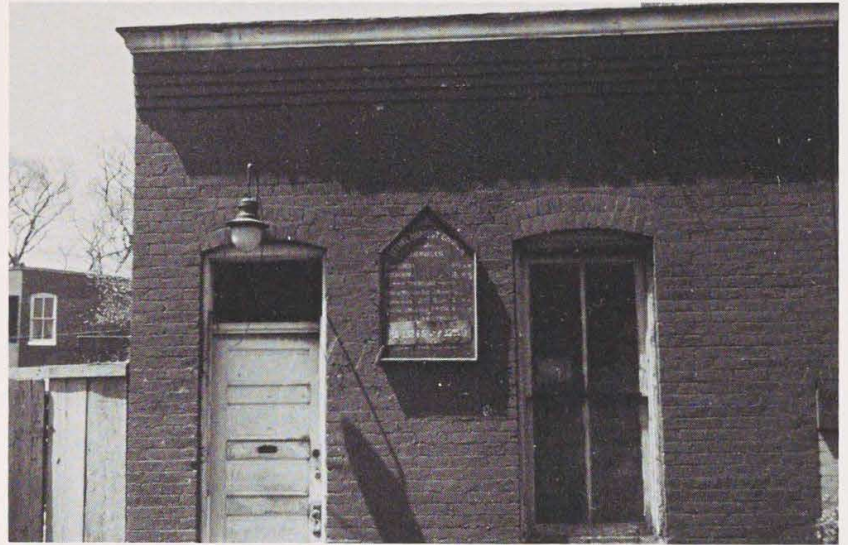

Figure 42 A church attended by colored residents of the Southeast section. Summer 1943. J. A. Horne. (Farm Security Administration Collection, Library of Congress)

\section{Other Aspects of Alley Life}

As Table 6 suggests, many aspects of alley life and culture eluded the photographer's camera, although occasional glimpses illustrate environment and behavior that are described in other sources. Alley houses shared the alley with other land uses including stables, blacksmith shops, and those of other artisans as well as occasional stores such as the one in Figure 45. Only a few photographs illustrate one of the most important institutions in alley life: religion. Printed sources are much more complete about decorations with religious motifs and other material culture of religion as well as the persistence of religious music among all residents; photographs only suggest the variety of religious experiences (see Figures 41 and 42). Finally, photographs do reveal considerable data and information on an important chore and form of employment of alley women: doing laundry (see Figures 5, 23, 28, 43, and 44), while the presence of carts throughout the compilation suggests the extent of both "carting" and the practice of scavenging (see Figure 36).

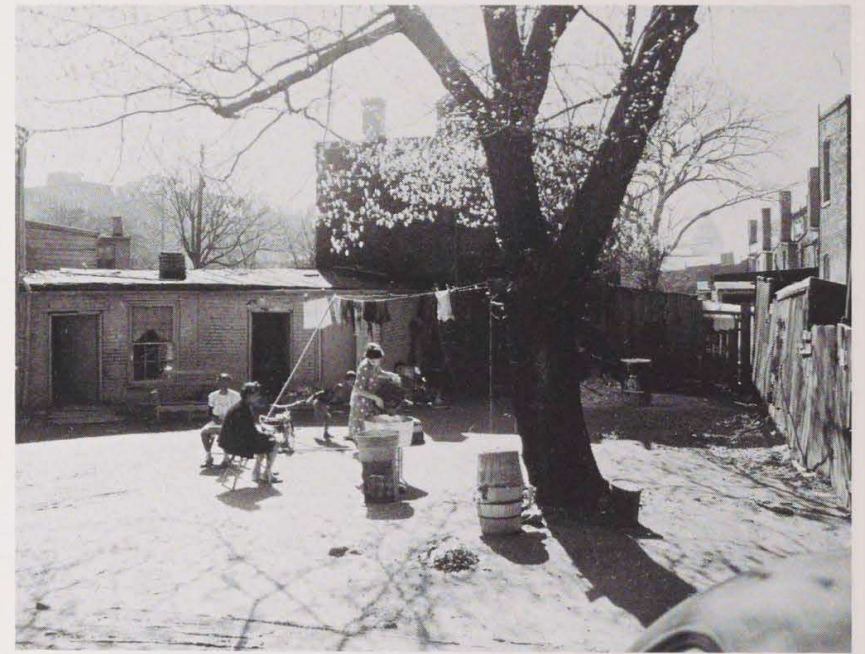

Figure 43 Washday in Washington slums in the Northwest (Johnson's Alley). March 29, 1949. National Capitol Housing Authority. (Library, Department of Housing and Community Development, Washington, D.C.)

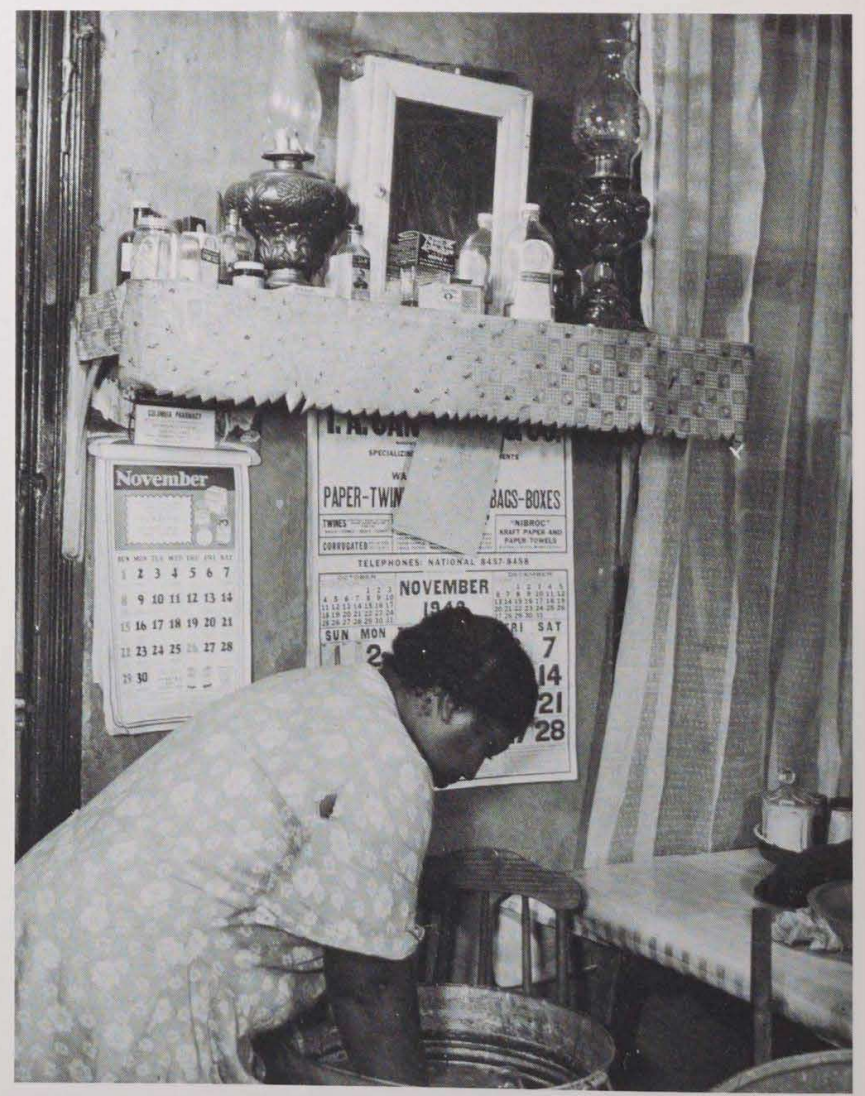

Figure 44 Negro woman washing clothes in her kitchen. November 1942. Gordon Parks. (Farm Security Administration Collection, Library of Congress) 


\section{Conclusions}

Historical photographs have a great deal to offer students of everyday life and groups at the bottom of complex societies. For developing and providing settings and contexts, photographs are a crucial source. They also represent virtually the only method to determine the material culture and behavior of groups that no longer live in the same circumstances and where historical archeology is not feasible. Most important, they are virtually alone in their ability to record the use of space and behavioral landscapes of residents. Nevertheless, there are many areas of life that are likely to be left out of photographic records.

Like any kind of raw data, photographs do not speak to the researcher except in the most general way, the presentation of the message or point of view of the photographer. This message or viewpoint represents a critical means to determine the bias of and to understand and control for what is likely to be left out, as well as to control for distortions in what is included. Beyond this, however, the researcher must approach photographs with the same questions as for any other data source. Because questions vary from researcher to researcher, photographs can be "reanalyzed" for new insights and information as well as for replication.

Although it is clear that historical photographs offer great potential as a source about some aspects of life, the researcher must take great care to determine the representativeness and areas of bias that result from the recording and collection processes. Most important, the the researcher should not rely solely on photographs any more than on any single type of source (Webb et al. 1966).

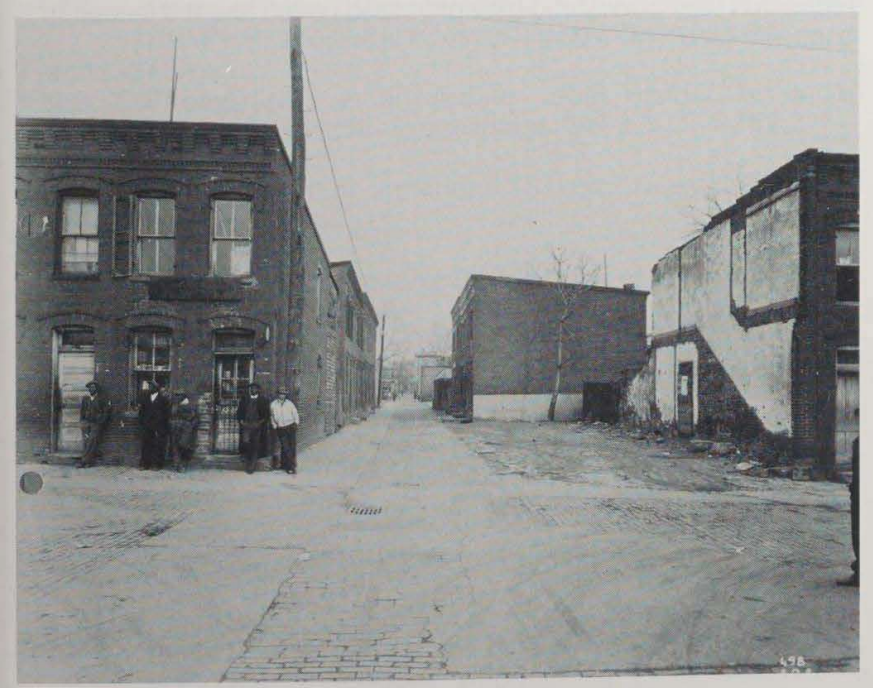

\section{Notes}

$\downarrow$ Original photo captions have been edited for this article

1 For examples of the analytical use of photographs by social scientists see Bateson and Mead 1947; Gesell 1934; Collier 1957; Mead and Byers 1968

2 This condition and tendency has made some subjects very difficult if not impossible for historians to study. Social histories of workingclass people (or others who left little or no written record) have been until recently almost impossible to do; Allan Spear (1967:x) noted that "historical materials are ill-suited for a systematic treatment of. the ghetto

3 Francis (1888) felt that "it is impossible that the immense worth and use of systematic and comprehensive photographic records of our country and our time can much longer fail to be recognized."

4 For example, Thomas Annan (1977) photographed the slums of Glasgow in the 1860s and 1870s, while John Thomson visually recorded similar conditions in 1870s London (Thomson and Smith 1877 ) and Jacob Riis (1971) covered New York City slums in the late 1880 s and 1890s. See also Szasz and Bogardus 1974; Thomas 1977; Holt 1971; Krim 1973; Gernsheim and Gernsheim 1970; and Newhall 1964

5 This discussion does not consider historical analyses that focus on myth and symbol such as the work of Michael Lesy (1973; 1976 1980), and Alan Trachtenberg (1979). It also does not consider studies of different photographic genres such as the daguerreotype (Rudisill 1971) or the stereograph (Earle 1979), although these latter works are important for background information on photoanalysis.

6 This article represents an expansion and reworking of the essay "Photographs and the Study of the Past" (Borchert 1980:269-303), which discussed the methods of analysis used in the initial study of 600 photographs (Borchert 1976). The current work expands the analysis to 898 photographs. I am greatly indebted to Dr. Susan Danziger for her help on the rewriting of this analysis.

7 Other subjects, especially the more affluent, would not be as well represented in the same sources as those considered here. Visual records are available, however, and probably in greater numbers (Novotny 1975; Weinstein and Booth 1977; Vanderbilt 1955; Shaw 1973). A useful guide to "Dating Photographs" is Baragwanath (1977). While no family photo albums were available for this study, analyses of this source are promising (Hirsch 1981; Musello 1977 1979, 1980; Noren 1973; Simpson 1976; Silber 1973; McLellan 1981; K. Ohrn 1975; S. Ohrn 1975; Davies 1977; Challinor 1979).

Figure 45 Navy Place SE.

February 27, 1939. Alley

Dwelling Authority.

(Library, Department of

Housing and Community

Development, Washing-

ton, D.C.) 
8 Of the published sources for photographs, Charles Weller's Neglected Neighbors (1909) was most valuable, and the visually oriented reform journal Charities/Charities and the Commons/ Survey was also useful. Original prints of alley life persist in the Lewis Wickes Hine Collection at the George Eastman House; the National Child Labor Committee Collection at the Division of Prints and Photographs of the Library of Congress; and the Roy E. Haynes Collection of prints of Willow Tree Alley in the John Ihlder Papers at the Franklin D. Roosevelt Library, Hyde Park, N.Y.

9 The Alley Dwelling Authority Collection (the agency was renamed the National Capitol Housing Authority) is now housed in the Library of the Department of Housing and Community Development of the D.C. Government, as are the Redevelopment Land Agency photographs. The Farm Security Administration Collection is housed in the Prints and Photographs Division, Library of Congress.

10 Washington Star photo files are at the newspaper offices; the Washington Daily News photo files are now part of the Washingtoniana Collection of the Martin Luther King Memorial Library (D.C.), which also holds a number of other photographs including the photograph contest held in 1947.

11 Other sources for visual records include the National Archives: Alley Dwelling Authority papers, National Capitol Housing Authority papers, and the National Capitol Planning Commission; Library of Congress: Street Survey Collection - District of Columbia (1900-1905); Franklin D. Roosevelt Library (Hyde Park): John Ihlder Papers (Director of the Alley Dwelling Authority)

12 As might be expected in cases where captions are nonexistent or contain minimal information, it is often quite difficult to know if a photograph is of an alley dwelling area or someplace else in the city. This is especially true for interior pictures. Sometimes it is possible to confirm the location by tracing sequences of photographs taken by a photographer or by identifying people or objects from other photographs. Nevertheless, there are undoubtedly some photographs included in the compilation that are not of alleys, while some were passed over and not included when they should have been

13 Because only the largest collections presented the problem of identifying which roll went with which captions, I manually combined captions and proof sheets. However, for collections that involve a number of rolls, it is recommended that the first frame on each roll be a photograph of a caption card identifying the roll number, date photograph taken, site, and collection name. This will greatly facilitate coordination and eliminate mistakes.

14 This was necessary to establish the location of interior photographs to determine that they were of alley houses. See note 11

15 The indices also have a further benefit for future users of the compilation. Other researchers who may have different interests -i.e., views of a specific location or the work of a particular photographer, or those concerned with child-rearing - can go directly to those enlargements for their own analyses. It also facilitates replication studies for other researchers.

16 Enlargements, save for publication, were not made of the R.L.A. collection (largely taken at time of demolition in the 1950s); the 1970 s surveys (35- $\mathrm{mm}$ prints were of sufficient quality for the type of analysis undertaken); and the Washington Star (restrictions placed on its use).

17 Following the reasoning of Sorenson (1971), copies of the entire compilation were donated to the Columbia Historical Society of Washington, D.C

18 This condition does not hold for other cities. See note 4 for some examples.
19 Most of the F.S.A. alley photographers came to the section already experienced photographers, although they also came from diverse backgrounds. Carl Mydans and Marion Post Wolcott arrived with prior work in journalism and photography. Arthur Rothstein had studied chemistry at Columbia University, done copy work for illustrations on American Economic Life for Stryker, and had exhibited his work locally. Ed Rosskam, who was initially in charge of the photographic files, came from the publishing industry. John Vachon, formerly a graduate student in English, worked his way up from messenger to picture classifier to photographer, while Gordon Parks, who had been a semipro athlete, railroad worker, and fashion and community photographer, joined the F.S.A. in its last year as a Rosenwald Fellow. Esther Bubly joined on the recommendation of Edward Steichen. See Hurley 1972:42, 110, 27-28, 100; Severin 1959:40, 27, 22, 29; Parks 1965:174-220.

20 These conditions along with a lack of an informed theory can lead to "work that is intellectually and analytically thin" (Becker 1974b:11).

21 The documentary tradition in America has been criticized for presenting "a specific political interpretation" that leaves out evidence of worker organization and struggle (Walker 1977:53,56) and for presenting "subjects" that are "simplified and ennobled - sentimentalized"; the photographs do not show "those who are poor through laziness or moral dereliction" (Stott 1973:57, 58-59). While there is some truth in these characterizations, it is clear that these assessments are based on the published work of the F.S.A., not the entire file of photographs. The F.S.A. work is much more diverse. More importantly for the analysis here, these characterizations do not go far enough in establishing the agendas and institutional controls on selection that operated in the F.S.A.

22 The caption of the first photograph read "A typical alley loafer needing instruction, stimulus, and opportunity"; while the second was 'Causes of Distress.' Five gin bottles from a dependent's home" (Weller 1909:276, 289). Moreover, these photographs share much in common with those that appeared during the same years in the American Journal of Sociology (Stasz 1979).

23 The analysis follows in modified form that suggested by Collier ( 1957 1979) and Wagner (1979).

24 The limited number of aerial views does not permit more sophisticated analyses suggested by Green (1955; 1956a; 1956b), Vogt (1974), Knowles (1966), and Norman and St. Joseph (1969).

25 While blue-collar residents use the alley as a place, middle-class residents of the 1970 s and 1980 s use the alley only as a path. The latter residents have extended protective barriers such as plants and small porches with sharp iron railings into the alley; filled up the windows with shutters, shades, curtains, and air conditioners; and redirected their activity into their privatized house and the fenced-in backyard (see Figure 24). 


\section{References}

- Annan, Thomas

1977 Photographers of the Old Closes and Streets of Glasgow 1868/1977. New York: Dover (reprint).

- Baragwanath, Albert K.

1977 Dating Photographs. Curator 20:42-47

- Bateson, Gregory, and Margaret Mead

1947 Balinese Character: A Photographic Analysis. New York New York Academy of Sciences.

- Becker, Howard

1974a Art as a Collective Action. American Sociological Review 39:767-776

1974b Photography and Sociology. Studies in the Anthropology of Visual Communication 1:3-26.

1978 Do Photographs Tell the Truth? Afterimage 5.9-13

- Borchert, James

1976 Alley Life in Washington: An Analysis of 600 Photographs. Columbia Historical Society Records 49:244-259.

1979 Alley Landscapes of Washington. Landscape 23:3-10.

1980 Alley Life in Washington: Family, Community, Religion, and Folklife in the City, 1850-1970. Urbana: IL: University of Illinois Press.

- Byers, Paul

1966 Cameras Don't Take Pictures. Columbia University Forum 9:27-31

- Challinor, Joan R.

1979 Family Photo Interpretation. In Kin and Communities: Families in America. Allan J. Lichtman and Joan R. Challinor, eds. Pp. 239-263. Washington: Smithsonian Institution Press.

- Collier, Jr., John

1957 Photography in Anthropology. American Anthropologist 59:843-859.

1979 Evaluating Visual Data. In Images of Information. Jon Wagner, ed. Pp. 161-169. Beverly Hills, CA: Sage.

- Daniel, Pete

1977 Deep'n as It Come: The 1927 Mississippi River Flood. New York: Oxford University Press

- Daniels, Douglas

1980 Pioneer Urbanites. Philadelphia: Temple University Press.

- Davies, Thomas L.

1977 Shoots: A Guide to Your Family's Photographic Heritage. Danbury, NH: Addison House.

- Earle, Edward W., ed.

1979 Points of View: The Stereograph in America: A Cultural History. Rochester, NY: Visual Studies Workshop Press.

- Francis, George E

1888 Photography as an Aid to Local History. American Antiquarian Society Proceedings. Ser. 2. 5:274-282.

- Gabriel, Ralph Henry, ed.

1926- The Pageant of America. 15 vols. New Haven: Yale 1929 University Press.

- Gardner, Alexander

1959 Gardner's Photographic Sketch Book of the Civil War. New York: Dover (reprint).

- Gernsheim, Helmut, and Alison Gernsheim

1970 The History of Photography. Englewood Cliffs, NJ: PrenticeHall.

- Gesell, Arnold

1934 An Atlas of Infant Behavior. 2 vols. New Haven: Yale University Press.

- Gower, H. D., Stanley Jast, and W. W. Topley

1916 The Camera as Historian. London: Sampson Low, Manston and Co

- Green, Norman E.

1955 Aerial Photography in the Analysis of Urban Structures, Ecological and Social. Unpublished Ph.D. dissertation, University of North Carolina.

1956a Scale Analysis of Urban Structures: A Study of Birmingham, Alabama. American Sociological Review 21:8-13. 1956b Aerial Photographic Analysis of Residential Neighborhoods: An Evaluation of Data Accuracy. Social Forces 35:142-147

- Gutman, Judith Mara

1967 Lewis W. Hine and the American Social Conscience. New York: Walker and $\mathrm{Co}$.

- Hall, Edward T.

1963 A System for the Notation of Proxemic Behavior. American Anthropologist 65:1003-1026

1974 Handbook for Proxemic Research. Washington: Society for the Anthropology of Visual Communication.

- Harney, Robert F., and Harold Troper

1975 Immigrants: A Portrait of the Urban Experience. Toronto: Van Nostrand Reinhold Co.

- Hine, Lewis W.

1938 Notes on Early Influences. In Elizabeth McCausland Papers. Roll 1256: 31, 92, 140. Archives of American Art. Smithsonian Institution.

- Hirsch, Julia

1981 Family Photographs: Content, Meaning, and Effect. New York: Oxford University Press

- Holt, Glen E.

1971 Chicago through a Camera Lens: An Essay on Photography as History. Chicago History 2:158-169.

- Hurley, F. Jack

1972 Portrait of a Decade: Roy Stryker and the Development of Documentary Photography in the Thirties. Baton Rouge: Louisiana State University Press.

1981 There's More than Meets the Eye: Looking at Photographs Historically. Center for Southern Folklore Magazine 3(3):6-7.

- Knowles, M. D.

1966 Air Photography and History. In The Uses of Air Photography. J. K. S. St. Joseph, ed. Pp. 127-137. New York: Day.

- Krim, Arthur J

1973 Photographic Imagery of the American City: 1840-1860. Professional Geographer 25:136-139.

- Lesy, Michael

1973 Wisconsin Death Trip. New York: Pantheon.

1976 Real Time. New York: Pantheon.

1980 Time Frames. New York: Pantheon

- McCord, Norman

1978 Photographs as Historical Evidence. The Local Historian 13:23-25

- McLellan, Marjorie

1981 A Look at the Family Album. Center for Southern Folklore Magazine 3(3):14.

- Marks, Robert W.

1939 Portrait of Lewis Hine. Coronet 5(4):147-157.

- Mayer, Harold, and Richard Wade

1969 Chicago: Growth of a Metropolis. Chicago: University of Chicago Press

- Mead, Margaret, and Paul Byers

1968 The Small Conference. The Hague: Mouton.

- Morison, Samuel Eliot

1967 The Materials of History. In Harvard Guide to American History. Oscar Handlin et al., eds. Pp. 64-68. New York: Atheneum.

- Musello, Christopher

1977 Home Mode Photography: A Study of Visual Interaction and Communication in Everyday Life. Unpublished M.A. thesis, University of Pennsylvania

1979 Family Photography. In Images of Information. Jon Wagner, ed. Beverly Hills, CA: Sage.

1980 Studying the Home Mode: An Exploration of Family Photography and Visual Communication. Studies in Visual Communication 6:23-42.

- Mydans, Carl

1981 Personal correspondence with author.

- Newhall, Beaumont

1964 The History of Photography from 1839 to the Present Day. New York: Museum of Modern Art. 
- Noren, Catherine

1973 The Camera of My Family. New York: Knopf

- Norman, E. R., and J. K. S. St. Joseph

1969 The Early Development of Irish Society: The Evidence of Aerial Photography. London: Cambridge University Press.

- Novotny, Ann

1975 Picture Sources 3. New York: Special Libraries Association.

- Ohrn, Karen Becker

1975 The Photoflow of Family Life: A Family's Photograph Collection. Folklore Forum 13:27-36

- Ohrn, Steve

1975 I've Been Duped: Reducing the Home-Made to Data. Folklore Forum 13:37-44

- Parks, Gordon

1965 A Choice of Weapons. New York: Harper and Row.

- Peters, Marsha, and Bernard Mergen

1977 "Doing the Rest:" The Uses of Photographs in American Studies. American Quarterly 29:280-303.

- Ratigan Marion M.

1941 A Sociological Survey of Disease in Four Alleys in the National Capital. Washington: Catholic University Press.

- Riis, Jacob

1971 How the Other Half Lives. New York: Dover (reprint).

- Robinson, James Harvey

1965 The New History. New York: Free Press (reprint)

- Rosenblum, Barbara

1978 Photographers at Work: A Sociology of Photographic Styles. New York: Holmes and Meier.

- Rothstein Arthur

1979 Words and Pictures. New York: American Photographic Book Publishing Co.

- Rudisill, Richard

1971 Mirror Image: The Influence of the Daguerreotype on American Society. Albuquerque: University of New Mexico Press.

- Rundell, Jr., Walter

1977 Early Texas Oil: A Photographic History, 1866-1936. College Station, TX: Texas A and M. University Press.

1978 Photographs as Historical Evidence: Early Texas Oil. American Archivist 41:373-398.

- Scherer, Joanna Cohen

1975 You Can't Believe Your Eyes: Inaccuracies in Photographs of North American Indians. Studies in the Anthropology of Visual Communication 2:67-79

- Schlereth, Thomas J

1980 Mirrors of the Past: Historical Photography and American History. In Artifacts and the American Past. Pp. 11-47. Nashville, TN: American Association for State and Local History.

- Schlesinger, Arthur M., Sr., and Dixon Ryan Fox

1927- A History of American Life. 13 vols. New York: Macmillan

1948

- Severin, Werner Joseph

1959 Photographic Documentation by the Farm Security Administration, 1935-1942. Unpublished M.A. thesis, University of Missouri.

- Shaw Renata V.

1973 Picture Searching: Techniques and Tool. New York: Special Libraries Association.

- Silber, Mark

1973 The Family Album. Boston: David R. Godine.
- Simpson, Jeffery

1976 The American Family: A History in Photographs. New York: Viking Press

- Smith, J.Russell

1925 North America. New York: Harcourt, Brace and Co

- Sorenson, E. Richard

1971 Toward a National Anthropological Research Film Center - A Progress Report. Program in Ethnographic Film Newsletter $3: 1-2$

1973 Research Filming and the Study of Culturally Specific Patterns of Behavior. Program in Ethnographic Film Newsletter 4:3-4

1976 The Edge of the Forest. Washington: Smithsonian Institution Press.

- $\quad$ and D. C. Gajdusek

1963 Investigation of Non-Recurring Phenomena. Nature 200: 112-117

- Spear, Allan

1967 Black Chicago. Chicago: University of Chicago Press.

- Spradley, James

1980 Participant Observer. New York: Holt, Rinehart and Winston.

- Stasz, Clarice

1979 The Early History of Visual Sociology. In Images of Information. Jon Wagner, ed. Pp. 119-136. Beverly Hills, CA: Sage.

- Stott, William

1973 Documentary Expression and Thirties America. London Oxford University Press

- Stryker, Roy

1935- Correspondence of Roy Stryker. Farm Security Administra-

1943 tion Collection. Historical Section-Division of Information. Archives of American Art. Smithsonian Institution.

1964a Interview by Richard K. Doud (June 13, 1964). Archives of American Art. Smithsonian Institution.

1964b Interview by Richard K. Doud (June 14, 1964). Archives of American Art. Smithsonian Institution.

1965 Interview by Richard K. Doud (January 23, 1965). Archives of American Art. Smithsonian Institution.

and Paul Johnstone

1940 Documentary Photographs. In The Cultural Approach to History. Caroline Ware, ed. Pp. 324-330. New York: Columbia University Press.

- Szasz, Ferenc M., and Ralph F. Bogardus

1974 The Camera and the American Social Conscience: The Documentary Photography of Jacob A. Riis. New York History 55:408-436

- Thomas, Alan

1977 Time in a Frame: Photography and the Nineteenth-Century Mind New York: Schocken.

- Thomason, Michael

1978 The Magic Image Revisited: The Photograph as a Historical Source. Alabama Review 31:83-91.

- Thomson, John, and Adolphe Smith

1877 Street Life in London. London: S. Low, Marston, Searle, and Rivington.

- Trachtenberg, Alan

1979 Photographs as Symbolic History. In The American Image Pp. ix-xxxii. New York: Pantheon.

- Tugwell, Rexford G., Thomas Munro, and Roy E. Stryker

1925 American Economic Life. New York: Harcourt, Brace.

- Vanderbilt, Paul

1955 Guide to the Special Collection of Prints and Photographs in the Library of Congress. Washington: Library of Congress.

- Vogt, Evon Z., ed.

1974 Aerial Photography in Anthropological Field Research Cambridge, Mass.: Harvard University Press.

- Wagner, Jon A.

1979 Avoiding Error. In Images of Information: Still Photography in the Social Sciences. Jon Wagner, ed. Pp. 147-159. Beverly Hills, CA: Sage. 
- Walker, Sam

1977 Documentary Photography in America: The Political Dimensions of an Art Form. Radical America 11:52-66

- Ware, Caroline, ed.

1940 The Cultural Approach to History. New York: Columbia University Press.

- Webb, Eugene J., et al.

1966 Unobtrusive Measures: Nonreactive Research in the Social Sciences. Chicago: Rand McNally.

- Weinstein, Robert A. and Larry Booth

1977 Collection, Use, and Care of Historical Photographs. Nashville, TN: American Association for State and Local History.

- Weller, Charles

1909 Neglected Neighbors. Philadelphia: John C. Winston.

- Wolcott, Marion Post

1965 Interview with Richard K. Doud (January 18, 1965). Archives of American Art. Smithsonian Institution.

1981 Personal correspondence with author.

- Worth, Sol, and John Adair

1972 Through Navajo Eyes: An Exploration of Film Communication and Anthropology. Bloomington: Indiana University Press. 